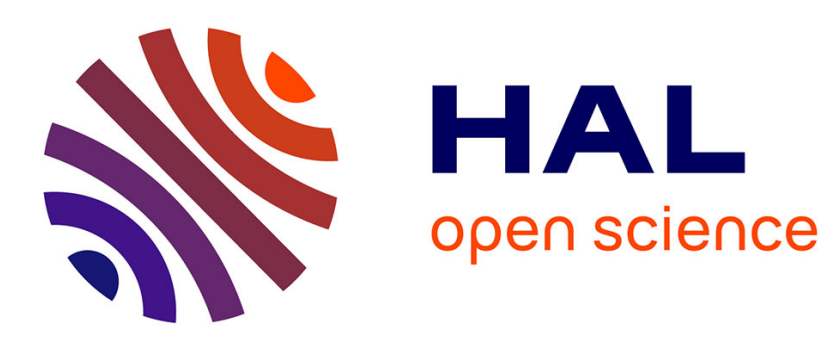

\title{
Laboratory studies of aeolian sediment transport processes on planetary surfaces
}

\author{
Keld R. Rasmussen, Alexandre Valance, Jonathan Merrison
}

\section{To cite this version:}

Keld R. Rasmussen, Alexandre Valance, Jonathan Merrison. Laboratory studies of aeolian sediment transport processes on planetary surfaces. Geomorphology, 2015, 244, pp.74-94. 10.1016/j.geomorph.2015.03.041 . hal-01150722

\section{HAL Id: hal-01150722 \\ https://hal.science/hal-01150722}

Submitted on 18 Nov 2015

HAL is a multi-disciplinary open access archive for the deposit and dissemination of scientific research documents, whether they are published or not. The documents may come from teaching and research institutions in France or abroad, or from public or private research centers.
L'archive ouverte pluridisciplinaire HAL, est destinée au dépôt et à la diffusion de documents scientifiques de niveau recherche, publiés ou non, émanant des établissements d'enseignement et de recherche français ou étrangers, des laboratoires publics ou privés. 


\title{
Laboratory studies of aeolian sediment transport processes
}

\section{on planetary surfaces}

\author{
Keld R. Rasmussen \\ Geoscience, Aarhus University, 8000 Aarhus C, Denmark \\ Email: geolkrr@geo.au.dk \\ *Corresponding author
}

Alexandre Valance

Institut de Physique de Rennes, Université de Rennes 1, 35042 Rennes, France, Email : alexandre.valance@univ-rennes1.fr

Jonathan Merrison

Department of Physics and Astronomy, Aarhus University, 8000 Aarhus C

Email: merrison@phys.au.dk

\begin{abstract}
We review selected experimental saltation studies performed in laboratory wind tunnels and collision experiments performed in (splash-) laboratory facilities that allow detailed observations between impinging particles on a stationary bed. We also discuss progress in understanding aeolian transport in nonterrestrial environments.
\end{abstract}


Saltation studies in terrestrial wind tunnels can be divided into two groups. The first group comprises studies using a short test bed, typically 1$4 \mathrm{~m}$ long, and focuses on the transitional behaviour near the upwind roughness discontinuity where saltation starts. The other group focuses on studies using long test beds — typically $6 \mathrm{~m}$ or more - where the saturated saltation takes place under equilibrium conditions between wind flow and the underlying rough bed.

Splash studies using upscaled model experiments allow collision simulations with large spherical particles to be recorded with a high speed video camera. The findings indicate that the number of ejected particles per impact scale linearly with the impact velocity of the saltating particles. Studies of saturated saltation in several facilities using predominantly Particle Tracking Velocimetry or Laser Doppler Velocimetry indicate that the velocity of the (few) particles having high trajectories increase with increasing friction velocity. However, the speed of the majority of particles that do not reach much higher than Bagnold's focal point is virtually independent of Shields parameter — at least for low or intermediate $u_{*-}$ values. In this case mass flux depends on friction velocity squared and not cubed as originally suggested by Bagnold. Over short beds particle velocity shows stronger dependence on friction velocity and profiles of particle velocity deviate from those obtained over long beds.

Measurements using horizontally segmented traps give average saltation jump-lengths near $60-70 \mathrm{~mm}$ and appear to be only weakly dependent on friction velocity, which is in agreement with some, but not all, 
older or recent wind tunnel observations. Similarly some measurements performed with uniform sand samples having grain diameters of the order of 0.25-0.40 $\mathrm{mm}$ indicate that ripple spacing depends on friction velocity in a similar way as particle jump length. The observations are thus in agreement with a recent ripple model that link the typical jump length to ripple spacing. A possible explanation for contradictory observations in some experiments may be that long observation sequences are required in order to assure that equilibrium exists between ripple geometry and wind flow.

Quantitative understanding of saltation characteristics on Mars still lacks important elements. Based upon image analysis and numerical predictions, aeolian ripples have been thought to consist of relatively large grains (diameter $>0.6 \mathrm{~mm}$ ) and that saltation occurs at high wind speeds $(>$ $26 \mathrm{~m} / \mathrm{s}$ ) involving trajectories that are significantly longer than those on Earth (by a factor of 10-100). However, this is not supported by recent observations from the surface of Mars, which shows that active ripples in their geometry and composition have characteristics compatible with those of terrestrial ripples (Sullivan et al., 2008). Also the highest average wind speeds on Mars have been measured to be $<20 \mathrm{~m} / \mathrm{s}$, with even turbulent gusts not exceeding $25 \mathrm{~m} / \mathrm{s}$.

Electrification is seen as a dominant factor in the transport dynamics of dust on Mars, affecting the structure, adhesive properties and detachment/entrainment mechanisms specifically through the formation of aggregates (Merrison et al., 2012). Conversely for terrestrial conditions electric fields typically observed are not intense enough to significantly 
affect sand transport rates while little is known in the case of extra-terrestrial environments.

Keywords: aeolian laboratory studies; saltation; splash; particle trajectory; ripple spacing; dust detachment

\section{Introduction}

Almost a century of research on aeolian processes has led to an overall understanding of wind flow and sediment transport systems and their interaction. A substantial part of the advances of our understanding has come from meticulous studies in the most commonly used aeolian laboratory — the wind tunnel. In an aeolian context a breakthrough in wind tunnel testing came during the 1930s where R.A. Bagnold in a series of studies obtained the first physically based insight into aeolian dynamics as documented in articles in the Proceedings of the Royal Society (Bagnold, 1936, 1937, 1938) and later in his famous book The Physics of Blown Sand and Desert Dunes (Bagnold, 1941). After the Second World War new wind tunnels for aeolian research were built and the purpose of wind tunnel facilities broadened so that subjects other than pure aeolian dynamics were included. In Japan Kawamura (1951) studied sand movement in a wind tunnel at Tokyo University. In North America in late fall of 1947, a study of the mechanics of wind erosion was initiated at Kansas State College, Manhattan, KS, USA, using laboratory and field (portable) wind tunnels 
(Zingg and Chepil, 1950; Chepil, 1965). In Denmark, at the Danish Technical University, Jensen (1954) investigated the aerodynamics of shelter belts in order to optimize the protection of fields during periods with little or no vegetation. During the 1960s and 1970s laboratory wind tunnels became more abundant; and in 1976 the first planetary facility 'The Martian Surface Wind Tunnel' (MARSWIT; Greeley, 1977) was put into operation in Ames, California by NASA. Although the number of terrestrial wind tunnels has been more or less stagnant since then, new or modified facilities now enable not only wind speed but also environmental parameters such as temperature (cryogenic), humidity (McKenna Neuman and Scott, 1998; McKenna Neuman and Sanderson, 2008), and electrification (Rasmussen et al., 2009; Merrison, 2012) to be investigated. In the planetary context two closed-circuit facilities have also come into use at Aarhus University (Rasmussen et al., 2011).

Initially wind tunnel laboratory studies focused on steady state saturated transport, i.e., the transport of particles on granular beds composed of plentiful dry, unconsolidated grains of sedimentary or artificial (industrial) origin. Bagnold (1941) recognized the existence of a fluid threshold for initiation of saltation and another, lower impact threshold above which saltation, once started, could be sustained. Influences on threshold conditions from, e.g., varying gravity, particle and gas density and composition were investigated in aeolian wind tunnels as well as in the MARSWIT facility (e.g., Iversen, 1976; Greeley et al., 1980; Iversen and White, 1982), and later the role of bed slope was also investigated (Iversen 
and Rasmussen, 1994). Bagnold (1941) linked mass transport $(q)$ to friction velocity $(u *)$ and suggested a cubic relation; subsequent modifications led to slightly different transport equations, e.g., Kawamura (1951), Lettau and Lettau (1978), and Owen (1964, 1980). Moreover, Bagnold (1941) observed that the feedback on the wind flow exerted by the saltating grains is equivalent to an increased friction (aerodynamic roughness length, $z_{0}$ ) of the bed; and from theoretical reasoning, Owen (1964) proposed that for a saltating bed $z_{0}$ increases with $u *^{2} / g$ where $g$ is gravitational acceleration. Experimental support of this came somewhat later (e.g., Rasmussen and Mikkelsen, 1991; Rasmussen et al., 1996). Bagnold also observed that the modification of the wind profile resulted in an almost constant velocity at some fixed height above the bed inside the region of intense saltation - the focal point.

As insight into saltation dynamics increased it became evident that a fundamental issue to solve was the physics involved in the collision process between impinging particles and the bed - expressed by the splash function (Unger and Haff, 1987). Although some information about the splash process (in the following referred to as the splash) initially came from high speed film recordings in wind tunnels (Willetts and Rice, 1986; Rice et al., 1996) another more valuable source of information was experiments performed in special splash facilities equipped with high-speed cameras (Mitha et al., 1986; Beladjine et al., 2007). A formal name, the splash law, was introduced by Anderson et al. (1991) specifying the probability of number and velocity distributions for rebounding and ejected grains. 
The terrestrial aeolian studies span a narrow fluid-dynamic range, and aeolian wind tunnels have undergone only small modification since the turn of the millennium. Planetary conditions, on the other hand, span an extremely broad range of dynamic conditions owing to varying pressure, temperature, and atmospheric composition — which impose large variation of density and viscosity and thus, indirectly, impose limitations on flow velocity, for instance. Parallel to this measuring, techniques and data analysis have advanced significantly and are the indirect cause for many recent advances within the aeolian field. Therefore the objectives of the present paper are to describe important developments in facilities and equipment and to highlight the contribution of laboratory experimentation to improve insight into aeolian dynamics and systems. We concentrate on active saltation of dry, loose, and unconsolidated materials; while aeolian systems where chemical bonding, cohesion, or adhesion plays an important role are beyond our experience. Initially in section 2 we discuss the state of wind tunnels and the design of equilibrium air and sediment flows as well as the concept of steady-state saltation by also including new experimental data. Section 3 focuses on the splash laboratory where modern high-speed video recorders have replaced the old film techniques (e.g., Beladjine et al., 2007) and data analysis greatly improved using modern digital image analysis rather than cumbersome visual inspection. Section 4 focuses on the transport layer and results obtained using vertically stacked traps, laser techniques spanning simple laser illumination of cross sections, to advanced techniques such as Laser Doppler Velocimetry (LDV) and Particle Tracking 
Velocimetry (PTV). Section 5 presents important observations from planetary environments and discusses some aspects of laboratory experiments in a planetary context; while finally in section 6 we discuss and conclude on important issues concerning laboratory-based simulation of aeolian systems. A list of symbols is given in Appendix A.

\section{Steady-state air flow and saltation in wind tunnels}

\subsection{The terrestrial aeolian wind tunnel}

A primary aim of an aeolian wind tunnel is to allow simulation of mechanics and transport of granular material ranging from dust to gravel size under the influence of wind flow in the atmospheric surface layer, i.e., the lowest part of the boundary layer between the surface of the Earth and the free flow in the overlaying atmosphere. Most wind tunnels are horizontal; but because in nature much sand transport takes place on sloping dune surfaces, at least one laboratory facility allows the slope of the bed to be varied within $\pm 25^{\circ}$ (Iversen and Rasmussen, 1994). Ideally wind tunnels should have as large a cross section as possible in order to let a turbulent boundary layer form with eddies at scales that are common in nature. However, in reality space and power constraints for the fan limit how large the cross sections can be made at a reasonable cost. One may distinguish between large tunnels where the width $(W)$ and the height $(H) \geq 1 \mathrm{~m}$, medium-sized tunnels where $0.5 \mathrm{~m} \leq W$ and $H \leq 1 \mathrm{~m}$, and small tunnels 
where $W, H<0.5 \mathrm{~m}$. A selection of tunnels representing these classes is listed in Table 1.

Owen and Gillette (1985) investigated the constraints on the development of saltation imposed by a wind tunnel of limited height and concluded that the Froude number $F r=U_{\infty}(g H)\left(U_{\infty}\right.$ being free stream velocity, $g$ acceleration of gravity, and $H$ tunnel height) should not be larger than 20. For a small $30-\mathrm{cm}$-high wind tunnel, this limits the free airstream velocity to $\sim 8 \mathrm{~m} / \mathrm{s}$ so that results from high friction velocity experiments may become dubious.

The turbulent spectrum in the tunnel must be as close as possible to that above a natural surface, but even for the largest tunnels a serious truncation of the low frequency end of the spectrum cannot be avoided. In contrast to this, the propagation of external disturbances into the wind tunnel is easier to remove by placing sets of screens and/or honeycombs at the entry to the working section. If the fan is placed downwind of the working section (suction-type tunnel; Table 1), a bell-mouth is usually placed at the tunnel inlet; whereas if the fan is placed upwind of the working section a suitable buffer volume with several screens followed by a contraction is efficient in removing unwanted external fluctuations (Bradshaw and Pankhurst, 1964). Both types of tunnel are suitable for aeolian studies, but a minor disadvantage of the suction-type tunnel may be that for a given fan speed the velocity may gradually decrease if the screens in the sedimentation chamber in front of the fan become clogged with (fine) particles during an experiment. 


\section{Table1}

Data for wind tunnels representing the range of dimensions which is typically found for aeolian studies. B: blower type; S: suction type; R: recirculating

\begin{tabular}{|c|c|c|c|c|c|}
\hline \multirow{2}{*}{ Location } & \multicolumn{3}{|c|}{ Dimension (m) } & \multirow{2}{*}{ Type } & \multirow{2}{*}{ Reference } \\
\hline & $\mathrm{W}$ & $\mathrm{H}$ & $\mathrm{L}$ & & \\
\hline $\begin{array}{l}\text { China, Lanzhou (Key Lab. of } \\
\text { Mechanics } \\
\text { on Disaster and Environment) }\end{array}$ & 1.3 & 1.45 & 20 & $\mathrm{~S}$ & Bo et al. (2013) \\
\hline $\begin{array}{l}\text { Kuwait (Kuwait Institute of } \\
\text { Scientific Research) }\end{array}$ & 1.2 & 0.92 & 25 & B & Al-Nassar et al. (2002) \\
\hline $\begin{array}{l}\text { China, Lanzhou (Lab. of Blown } \\
\text { Sand Phys. and Desert Environ.) }\end{array}$ & 1.2 & 1.2 & 21 & B & Dong et al. (2004) \\
\hline Canada, University of Guelph & 0.92 & 0.76 & 8 & $\mathrm{~B}(\mathrm{R})$ & Bauer et al. (2004) \\
\hline Canada, University of Trent & 0.71 & 0.76 & 13.8 & $\mathrm{~S}$ & $\begin{array}{l}\mathrm{Li} \text { and McKenna } \\
\text { Neuman (2014) }\end{array}$ \\
\hline Israel, Beersheva & 0.70 & 0.70 & 7 & $\mathrm{~S}$ & Pye and Tsoar(2009) \\
\hline $\begin{array}{l}\text { Denmark, Aarhus University: } \\
\text { Horizontal tunnel } \\
\text { Sloping tunnel }\end{array}$ & $\begin{array}{l}0.6 \\
0.35\end{array}$ & $\begin{array}{l}0.9 \\
0.5\end{array}$ & $\begin{array}{c}20 \\
6\end{array}$ & $\begin{array}{l}\mathrm{S} \\
\mathrm{S}\end{array}$ & $\begin{array}{l}\text { Rasmussen et al. } \\
\text { (2011) }\end{array}$ \\
\hline $\begin{array}{l}\text { France, École polytechnique de } \\
\text { l'université de Nantes }\end{array}$ & 0.3 & 0.3 & 6 & B & Ho et al. (2014) \\
\hline
\end{tabular}

\subsection{Steady state air flow}

An aeolian tunnel must allow proper simulation of processes at the interface between Earth and Atmosphere. Therefore a boundary layer having suitable characteristics for a given experiment must be produced upwind of the working section and, for practical reasons, over as short a distance as possible. The most common method for documenting the dynamic state of 
this boundary layer is and has long been the pitot-static tube connected to a differential precision manometer.

The friction velocity of a boundary layer is $u_{*}=(\tau / \rho)^{1 / 2}$ where $\tau$ is the bed shear stress and $\rho$ is air density. For a turbulent boundary layer with constant bed stress, the vertical gradient of the velocity component $(u)$ in the mean flow direction is required to have a log-linear segment (White, 1991):

$$
\frac{\partial u}{\partial(\ln z)}=\frac{u_{*}}{\kappa}
$$

The von Karman constant $\kappa=0.4$.

For a fixed sand bed (i.e., no saltation), we can determine the state of the flow near the bed using the dimensionless roughness factor (roughness Reynolds number):

$$
R_{*}=\frac{k_{s} u_{*}}{v}
$$

where $k_{s}$ is the equivalent grain roughness (Brutsaert, 1982), and $v$ is the kinematic viscosity of the air. A bed is (aerodynamically) smooth if $R *<5$. Thus for a flow where $u_{*}=0.25 \mathrm{~m} / \mathrm{s}$ and $v=2 \times 10^{-5} \mathrm{~m}^{2} / \mathrm{s}$, the bed will be aerodynamically smooth when the sand roughness $k_{s} \leq 0.4 \mathrm{~mm}$. As a plausible assumption, we use $k_{s}=D_{p}$ (Camenen et al., 2006). A (flat) bed composed of typical wind-blown sand with $D_{p}=0.25 \mathrm{~mm}$ will be aerodynamically smooth below the saltation threshold. In this case the flow 
depends on viscosity $(v)$, and there will be a laminar sublayer near the bed where the dimensionless velocity $\left(u(z) / u_{*}\right)$ will increase linearly with the dimensionless height $\left(\ln \frac{z}{v / u_{*}}\right)$. Above the laminar sublayer the dimensionless velocity scales linearly with the logarithm of dimensionless height (Fig. 1A).
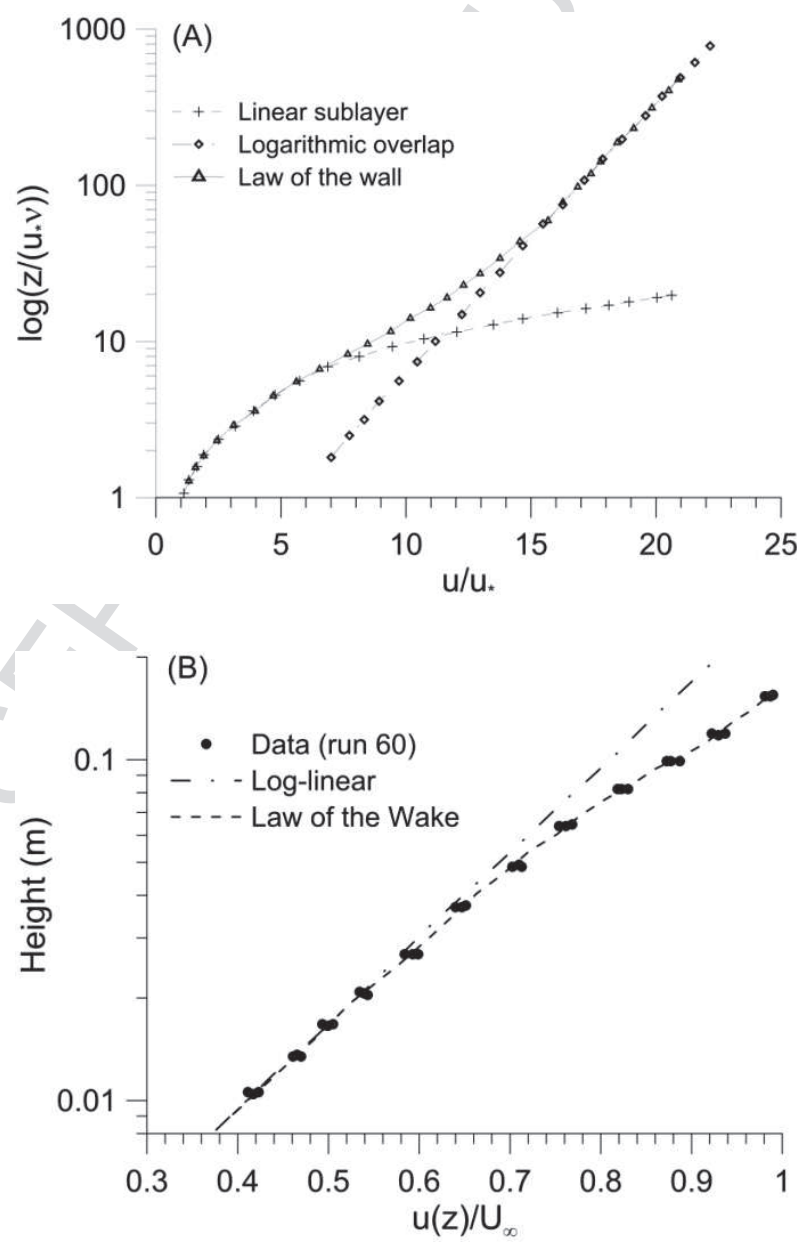

Fig. 1. (A) The boundary layer above a smooth bed in a wind tunnel showing the linear sublayer and the logarithmic overlap regions. The 
representation of the dimensionless velocity profile by the 'Law of the Wall' (Spalding, 1961) is also indicated (modified after White, 1991).

(B) Dimensionless wind speed profile $\left(\mathrm{u}(\mathrm{z}) / \mathrm{U}_{\infty}\right)$ measured above a rough bed (fixed roughness, $U_{\infty}$ is free stream velocity). The logarithmic wind profile (Eq. 4a) and the 'Law of the Wake' (Coles, 1956) are also shown.

The logarithmic region extends from a height of $z>30 \mathrm{v} / \mathrm{u} *$ above the surface - which approximately corresponds to $3 \mathrm{~mm}$ for the values given above. One should note that in a semi-log plot, the zero intercept of the mean velocity vs height is $z_{0 M}=0.135 v / u *$, which may serve as a useful control of the velocity profile (Brutsaert, 1982). For grains larger than about $0.4 \mathrm{~mm}$, the bed condition is complex (the transition regime, Schlichting, 1979), but also unusual in the present context and therefore it will not be considered here.

When saltation is active the boundary layer conditions change abruptly because the bed becomes rough — even for the finest sand particles. According to Owen (1964) the roughness length $z_{0}$ depends on saltation intensity; and he suggested that

$$
z_{0}=C u_{*}^{2} \frac{2}{g}
$$

Later experiments give support to this (e.g., Sherman, 1992; Rasmussen et al., 1996), and for different friction velocities and grain size 
their values of $C$ range between 0.04 and 0.06 for fully developed saltation. Thus for the fully turbulent boundary layer, the wind speed variation $u(z)$ with height $(z)$ in the logarithmic overlap region is described by the logarithmic wind law (White, 1991):

$$
u(z)=\frac{u_{*}}{\kappa} \ln \frac{z}{z_{0}}
$$

If inserting Eq. (3) into Eq. (4a), we get the velocity profile for a rough granular bed with saltation:

$$
u(z)=\frac{u_{*}}{\kappa} \ln \frac{2 g z}{C u_{*}^{2}}
$$

indicating that the friction velocity is not linearly proportional to the free stream velocity in the tunnel as is the case for fixed bed roughness.

The downstream development of a natural equilibrium boundary layer is slow, and the logarithmic overlap region will be shallow unless the boundary layer is artificially thickened. Rasmussen et al. (2011) inserted a combination of turbulence spires and roughness arrays downwind of the screen(s) in the entry, while McKenna Neuman (2004) used roughness arrays only. For any given combination of friction velocity $(u *)$ and aerodynamic roughness length $\left(z_{0}\right)$, turbulence spires can be designed following guidelines given by Irwin (1981); while Raupach et al. (1991) set out how sparse roughness arrays can conveniently be designed using the 
aspect ratio (frontal area/areal block density). For friction velocities selected in the range between 0.2 and $0.75 \mathrm{~m} / \mathrm{s}$, the value of $z_{0}$ falls in the range of $4 \times 10^{-5}$ to $1.1 \times 10^{-3} \mathrm{~m}$ with a corresponding variation of $R *$ between 0.5 and 35 - so one should note that near and slightly above the saltation threshold true $z_{0} / u *$ scaling may not be found.

When the boundary layer forms in the wind tunnel under a mild pressure gradient, a slight wake will form and influence the wind profile in the logarithmic overlap region — in particular its upper part (Fig.1B). To correct for this, Coles (1956) proposed the Law of the Wake:

$$
u(z)=\frac{u_{*}}{\kappa}\left[\ln \left(\frac{z}{z_{0}}\right) \times \Pi \times 2 \sin ^{2}\left(\frac{\Pi}{2} \frac{z}{\delta}\right)\right]
$$

where $\Pi$ is Coles' wake parameter that depends on the horizontal pressure gradient, and $\delta$ is the boundary layer thickness. In wind tunnels with a small cross section or generally when the flow speed becomes very high, this will bias the estimation of $u *$ and $z_{0}$ unless properly corrected for. White (1991) has outlined a method to compensate for the influence using observations of the velocity profile and the horizontal pressure gradient in the working section. However, measuring the horizontal pressure gradient with high accuracy has not gained common practice in aeolian studies although the influence from the wake can be observed in many studies (e.g., McKenna Neuman and Nickling, 1994; Bauer et al., 2004). Using Coles (1956) Law of the Wake on velocity profile data recorded in a rather small wind tunnel, 
Rasmussen et al. (1996) used $\Pi$-correction according to White (1991) and found good experimental agreement between observed and predicted wind speed data (Fig. 1B). Although the wind speed profiles observed by Bauer et al. (2004) have a noticeable influence of the slight wake, their calculated $\Pi$ values vary somewhat and show less systematic behaviour. Finally we shall mention that the velocity profiles recorded by Dong et al. (2003) differ from most other wind tunnel profiles because in their study the transition to the free flow seems undetectable despite that measurements have been made up to almost half the height of the wind tunnel.

In addition to the wake influence on the upper part of the logarithmic overlap region, the saltation cloud may significantly influence the lower part of the velocity profile. Thus when extrapolated to the logarithmic $y$-axis in a $\log$ linear plot of $\log (z)$ vs. $u$, the velocity profiles will intersect in a focus region within the transport layer. However, the velocity profile in the focus region is modified by the grain-borne shear stress, i.e., the momentum carried by the saltation grains (Bagnold, 1941): and based on numerical calculations, Durán et al. (2011) found that the wind speed and the height at the focal point depends on grain size but typically is near $2 \mathrm{~m} / \mathrm{s}$ at an elevation of about $10 \mathrm{~mm}$ above the bed. Ho et al. (2014) found corresponding values of height and velocity to be $8 \mathrm{~mm}$ and $2.8 \mathrm{~m} / \mathrm{s}$, respectively, $13 \mathrm{~mm}$ and $5.0 \mathrm{~m} / \mathrm{s}$ for sand samples with grain diameter 0.23 $\mathrm{mm}$ and $0.63 \mathrm{~mm}$.

\subsection{Steady-state saltation flux}


Two different but not independent problems are involved in assuring that steady state mass transport exists in a laboratory experiment. Firstly, what is the optimum design of the laboratory facility, and secondly how can one actually document that temporal and spatial variations have been removed from the flow?

First consider a system with steady-state saltation that is in balance with the wind flow. The response to a sudden (step) increase in wind flow is a gradual change in mass transport toward a new asymptotic equilibrium or saturated value $(q)$. It requires a certain time (or distance) to reach the saturated value - this is specified by the time constant or the saturation length $\left(l_{s a t}\right)$ of the system, which is the distance needed before mass flow is $\left(1-e^{-1}\right) \times q$ or near $63 \%$ of the new equilibrium value. Based on laboratory experiments, Andreotti et al. (2010) found that $l_{\text {sat }}$ is of the order of a half meter for a sand having $D_{p}=0.2 \mathrm{~mm}$. Therefore the saturated value will be reached within $\sim 1.5 \mathrm{~m}$. If at the upwind end of the bed saltation flux is zero, Andreotti et al. (2010) found that an additional distance is required for saltation to build up through the cascading reaction. Based on their experiment they find that the total distance downwind of the entry — the fetch length $L_{F}$ (Gillette et al., 1996) - needed for saltation to reach the saturated value is $\sim 2 \mathrm{~m}$. Notably, earlier wind tunnel studies using somewhat longer tunnels (Walker, 1981; Shao and Raupach, 1992; Gillette et al., 1996) and numerical simulation (Shao and Li, 1999) indicated that $L_{F}$ is of the order of $15 \mathrm{~m}$ or more. 
Despite the scatter in results, it is obviously important that $L_{F}$ is minimized. This requires a careful design of the tunnel inlet and feeding sand while (artificially) adding momentum to the grains. When feeding sand, a problem is to balance distortion of the airflow by the feeder mechanism and actually feed the grains with a proper momentum distribution. Ideally grains should be fed with a spatial variation of rate and velocity corresponding to that of the saltation cloud in a very long working section. However, after a number of inconclusive tests in the Aarhus tunnel where design-tubes having different shape and density were tested, a relatively simple solution has been implemented. Feeding is performed onto the hard surface of the roughness array $0.5 \mathrm{~m}$ upstream of the leading edge of the sand bed. The sand emerges through 4 circular tubes $(\mathrm{OD}=10 \mathrm{~mm})$ that terminate $\sim 200 \mathrm{~mm}$ above the bed for friction velocities $u *<0.35 \mathrm{~m} / \mathrm{s}$; 6 tubes that terminate $\sim 125 \mathrm{~mm}$ above the bed for friction velocities in the range $0.35 \leq u * \leq 0.65 \mathrm{~m} / \mathrm{s}$ while they terminate at $100 \mathrm{~mm}$ for high friction velocities $u *>0.65 \mathrm{~m} / \mathrm{s}$. With this configuration, erosion pins placed at $1-\mathrm{m}$ intervals downwind of the leading edge show changes in bed elevation $(>1$ $\mathrm{mm}$ ) within the first $3 \mathrm{~m}$ for low friction velocities and up to $7 \mathrm{~m}$ for the highest friction velocities. When friction velocity exceeds $0.7 \mathrm{~m} / \mathrm{s}$, depletion of sand at the upstream end of the sand bed will occur after 10 to $30 \mathrm{~min}$ and quickly propagate downstream, thus limiting the duration of continuous experiments using the present feeding system.

When saltation starts from a bed that initially is flat, Bagnold (1941) observed that embryonic ripples appear quickly and simultaneously with 
accumulation of the coarsest grains in the crest region and gradually increasing ripple amplitude/wavelength. During this transient but short phase, a slight change in skin friction from the bed/ripples may occur, which in turn might cause some (minor) adjustment of the transport rate. Likewise a gradual long-term change of the geometry of the ripples may influence transport rate. Therefore Rasmussen and Mikkelsen (1991) used isokinetic sampling with vertically stacked traps on a prerippled bed composed of dune sand having diameter $D_{p}=0.225 \mathrm{~mm}$. Although grains were fed into the tunnel at a constant rate, they observed that during the first 30 min the sand flux was constant, but then it showed a small (5\%) decrease after $40 \mathrm{~min}$ while after 75 min the flux had dropped to about $75 \%$ of the initial rate. Based on this, Iversen and Rasmussen (1999) prerippled the bed during 5-10 min and restricted maximum run time to $30 \mathrm{~min}$. Initially prerippling was done in order to avoid possible transitional influences during the change from the flat bed to the rippled bed, although such influences could not be detected because of the poor temporal resolution of the trap data. However, we can add that McKenna Neuman and Nickling (1994) used a fixed 10-min prerippling interval in their wind tunnel experiments. However, detailed information on the procedure used before and during runs is far from available for all wind tunnel experiments despite that this may seem relevant.

In order to cast additional light on the long-term stability of mass transport we include observations recently made in the Aarhus wind tunnel using two different sand beds composed of uniform sand samples 
respectively with diameters of 0.180 and $0.320 \mathrm{~mm}$. Starting with a flat bed, the rate of grains passing the measuring volume of a laser-Doppler anemometer (see section 4) during intervals from $\sim 3$ to $50 \mathrm{~s}$ is recorded at three elevations. This is repeated 2-4 times at three different friction velocities. For each height and friction velocity, the grain rate measured during the first observation interval is used to normalise the observed rates during the following observation intervals thus defining the relative rate (Fig. 2). The measuring intervals have different length because decreasing volume fraction with height requires longer sampling times. For the lowest friction velocity recording starts at the lowest level and continues at the next level if either 1000 grains have been counted or $50 \mathrm{~s}$ have passed. For the higher friction velocities the corresponding limits are 2000 grains and $40 \mathrm{~s}$. The data show considerable scatter — especially for the smallest grains. No clear trend is visible, but it may seem possible that there is a slight increase in the relative rate during the initial phase when the ripples evolve. Some of the outliers are probably associated with bursts of grains following a strong gust sweeping into the near-bed region.

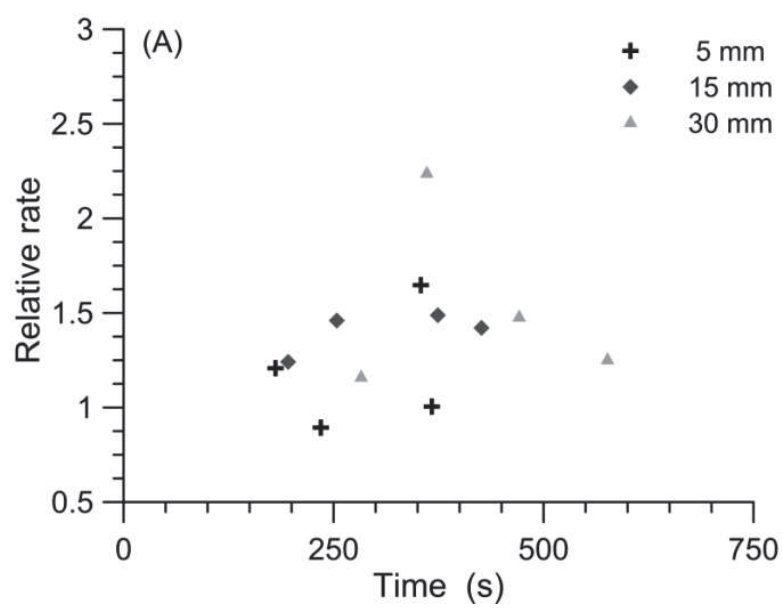




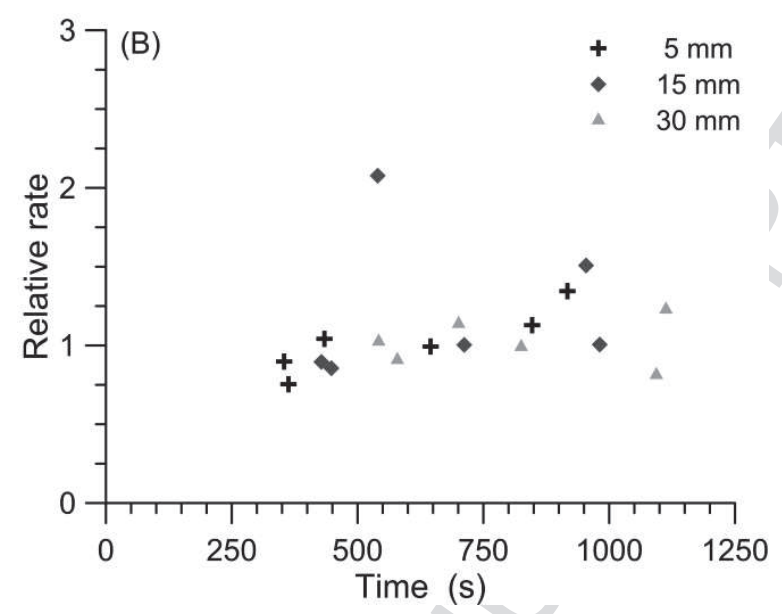

Fig. 2. The relative grain rate at 3 heights and 3 friction velocities $(u *)$ above 2 beds of uniform quartz grains having diameter $\left(D_{p}\right)$ : (A) $D_{p}=0.18 \mathrm{~mm}$; $u_{*}=0.27,0.53,0.70 \mathrm{~m} / \mathrm{s}$; and (B) $D_{p}=0.32 \mathrm{~mm}, u_{*}=0.29,0.50,0.68 \mathrm{~m} / \mathrm{s}$ ).

For the three $u *$-values, the ripple pattern is not stable after $600 \mathrm{~s}$ (section 4). Therefore long-term observation of transport rate was made using the $0.320-\mathrm{mm}$ sample. The relative mass transported through the working area during a series of $10-\mathrm{min}$ periods $\left(u_{*}=0.29 \mathrm{~m} / \mathrm{s}\right.$ and $u_{*}=0.50$ $\mathrm{m} / \mathrm{s})$ or $20-\mathrm{min}$ periods $\left(u_{*}=0.68 \mathrm{~m} / \mathrm{s}\right)$ are depicted in Fig. 3. At each friction velocity, the relative mass flux is found from normalizing the observed mass fluxes during a period with that collected during the last period, and data indicate that transport at the lower $u *$-values apparently decreases until $\sim 1 \mathrm{~h}$ has passed and a steady ripple pattern has developed. In our opinion it is likely that for sand beds composed of uniform grains the change in mass transport is caused by a slight increase in form drag resulting from the development of the stable ripple pattern. For the bed 
composed of dune sand (Rasmussen and Mikkelsen, 1991), which has a larger variation in grain size than the uniform distributions described above, the change in mass transport is more substantial than for the uniform beds. However, on beds with a broad size distribution a thin coarse layer may form on the ripple crests (e.g., Walker, 1981). Such size segregation could influence the temporal changes of mass transport, but we are not aware of any clear documentation of this.

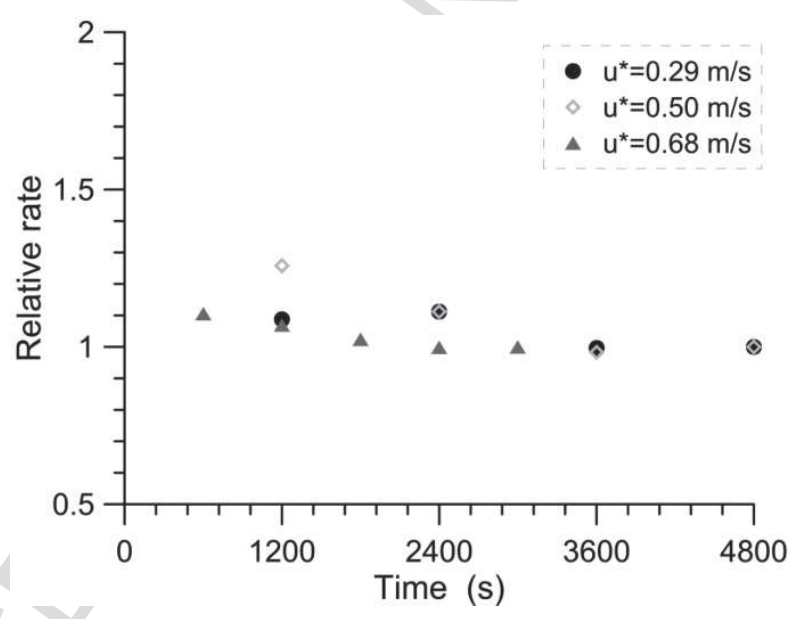

Fig. 3. The relative mass flux measured at different friction velocities $(u *)$ downstream of a bed composed of uniform quartz grains: $D_{p}=0.32 \mathrm{~mm}$.

The measurements presented in Figs. 2 and 3 represent techniques that together with sampling using vertically segmented traps have been used for many years to acquire information about total mass transport. Some segmented traps and mass collector traps have been equipped with electronic devises to continuously monitor the catch and some point sampling methods use sound (micro-/miniphone sensor; Ellis et al., 2009) or 
piezoelectric crystals (Gillette and Stockton, 1986) rather than LDVinformation to record the passage of a grain. Nevertheless, systematic bias in the sampling are associated with all the sampling devices mentioned above. The vertically segmented trap underestimates flux considerably near the surface (Nickling and McKenna Neuman, 1997; Rasmussen and Mikkelsen, 1998). So far we have been unable to acquire precise and reliable laser Doppler velocity measurements close to the surface where the flux is highest and validation poor (Rasmussen and Sørensen, 2008) - this may be because of strong back-scatter of the laser signal from bed particles. Likewise several of the sound/piezoelectric sensors underestimate flux because of deficiencies in sensitivity (Sherman et al., 2011). Finally variation in the flux across the tunnel complicates comparison between total mass collector data and flow measurements made at the centre-line of the tunnel (Williams, 1964; Iversen and Rasmussen, 1999; Ho et al., 2014).

\section{The splash laboratory}

The impact of particles onto the bed has been recognized for a long time to be an important process that drives saltation transport. As a saltating particle impacts the bed, it generally rebounds and produces ejection of particles from the bed (the so called ejecta or splashed particles) when it is fast enough. Many experimental (Mitha et al., 1986; Willetts and Rice, 1986, 1989; Werner, 1990; Nalpanis et al., 1993; Rioual et al., 2003; Beladjine et al., 2007; Ammi et al., 2009) and numerical (Anderson and Haff, 1988; 
Werner and Haff, 1988; Anderson et al., 1991; Oger et al., 2005; Crassous et al., 2007) studies have been devoted to the splash process. We shall provide here the main salient features, and because we shall consider particles of different diameter $\left(D_{p}\right)$, we shall also introduce Shields parameter (or Shields number) $S^{*}=\tau /\left(\left(\rho_{s}-\rho\right) g D_{p}\right)$ where $\tau$ is the shear stress, $\rho_{s}$ and $\rho$ are particle density and air density, and $g$ is gravity.

Owing to the experimental difficulty of tracking particles within a dense saltation layer only few in-situ measurements of the impact process during steady and fully developed states of saltation transport have been made. The in situ measurements are achieved in wind tunnels at low Shields parameter (i.e., slightly above the threshold of transport in order to have a dilute transport layer) using high speed video recordings (Willetts and Rice, 1986, Nalpanis et al., 1993). Willetts and Rice (1986) found in particular that the impacting grains hit the sand surface at small angles between $10^{\circ}$ and $16^{\circ}$ and rebound with an angle between $20^{\circ}$ and $40^{\circ}$. In addition, they established that the grains ejected from the granular bed have an average speed of one order of magnitude less than the impacting speed. 


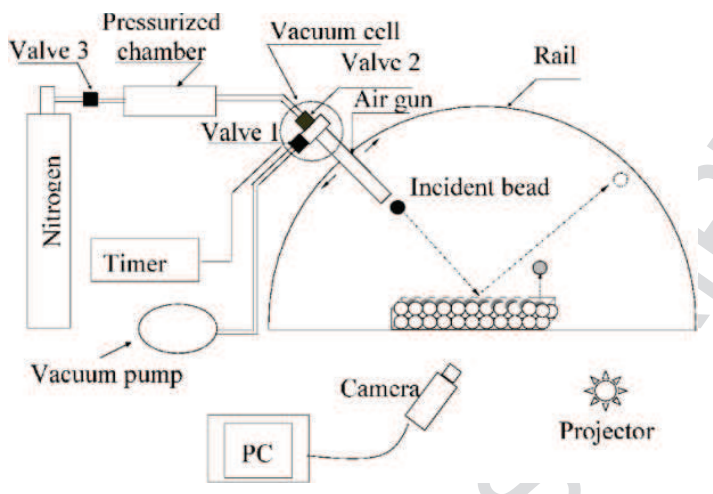

Fig. 4. Experimental setup for model splash experiments from Beladjine et al. (2007): An air gun is used to propel a single particle onto a packing of like particles. The air gun can move on a semicircular rail that allows the incident angle to be varied from $0^{\circ}$ to $90^{\circ}$. By varying the pressure, the speed of the incident can be adjusted to a given value. Particles used for these experiments are spherical PVC beads (6 $\mathrm{mm}$ in diameter).

To circumvent the difficulty of in situ measurements, many model collision experiments have been developed (Mitha et al., 1986; Rioual et al., 2003; Beladjine et al., 2007; Ammi et al., 2009). The principle of these model experiments is to propel a single particle, at a given impact velocity and angle, onto a granular packing of like particles (see Fig. 4). These experiments were generally performed with model particles, spherical and larger than sand grains, to facilitate the manipulation and the particle tracking analysis. Similitude laws for the collision process are based on the Froude number defined as $F r=V_{i} /\left(g D_{p}\right)^{1 / 2}$ where $V_{i}$ is the impact velocity and $D_{p}$ is the median diameter of the particles. In standard conditions of 
aeolian sand transport with $0.200-\mathrm{mm}$ grains, the impact velocities of the saltating grains range from 1 to $5 \mathrm{~m} / \mathrm{s}$. The Froude number therefore lies between 20 and 100. For example, using 6-mm particles as in Beladjine et al. (2007) requires impact speed ranging from 10 to $50 \mathrm{~m} / \mathrm{s}$. An example of a typical collision of a 6-mm particle impacting a granular packing of like particles at the speed of $18 \mathrm{~m} / \mathrm{s}$ is shown in Fig. 5 (Beladjine et al., 2007). We clearly identify two distinct processes: (i) the rebound of the impact particles and (ii) the set of splashed particles with a much smaller speed than the rebound particle.
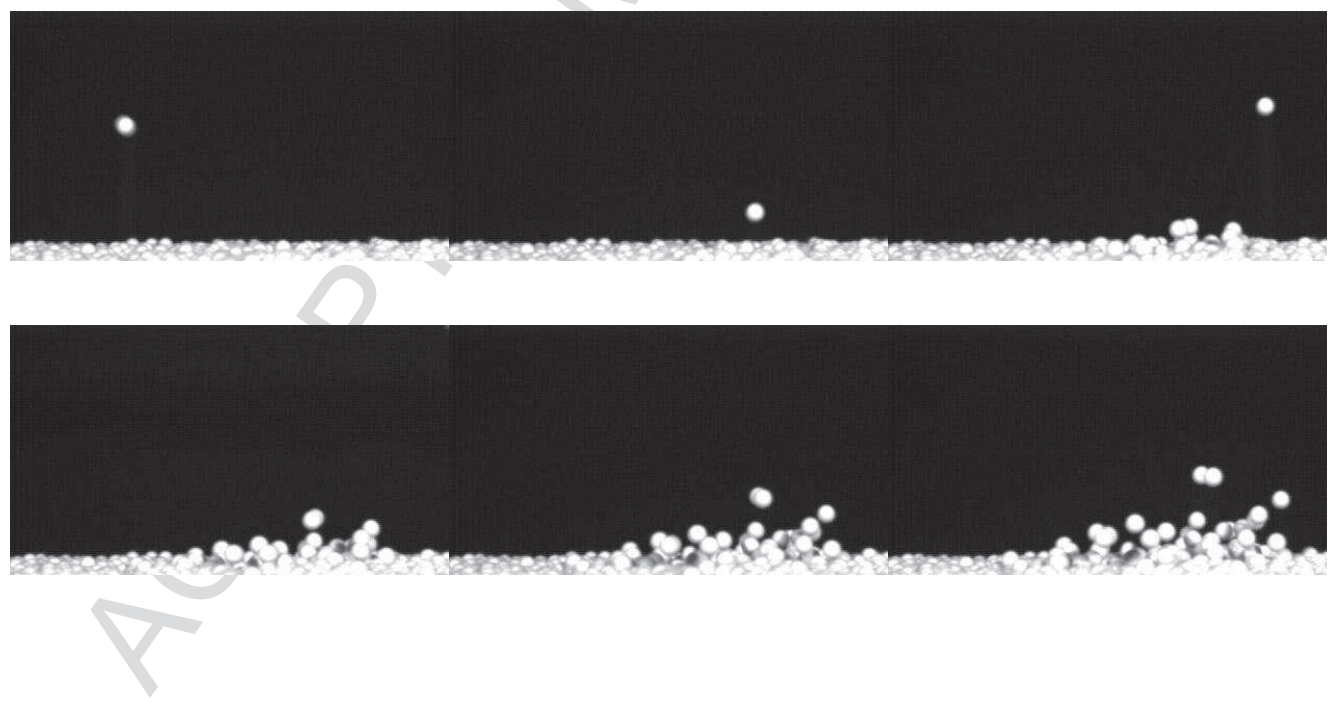

Fig. 5: Successive snapshots of a collision of a 6-mm particle onto a granular packing of like particles (experiments by Beladjine et al., 2007). The impact velocity and angle are, respectively, $V_{i}=74(g d)^{1 / 2}=18 \mathrm{~m} / \mathrm{s}$, and $\theta_{1}=40^{\circ}$ for this collision. The time step between two successive images is $4 \mathrm{~ms}$. 
On the basis of the model collision experiments, important features for the rebound particle and for the splashed particles have been identified and are summarized below. Numerical simulations based on discrete element method (DEM) (Anderson and Haff, 1988; Werner and Haff, 1988; Anderson et al., 1991; Oger et al., 2005; Crassous et al., 2007) generally confirm the experimental outcomes.

\subsection{Rebound}

According to results of model collision experiments (Beladjine et al., 2007), the rebound process is only specular for a narrow range of impact angles near $20^{\circ}$. For lower (grazing) impact angles the rebound angle is greater than the incident angle; whereas for impact angles higher than $20^{\circ}$, the rebound angle is less than the incident one (Fig. 6A).

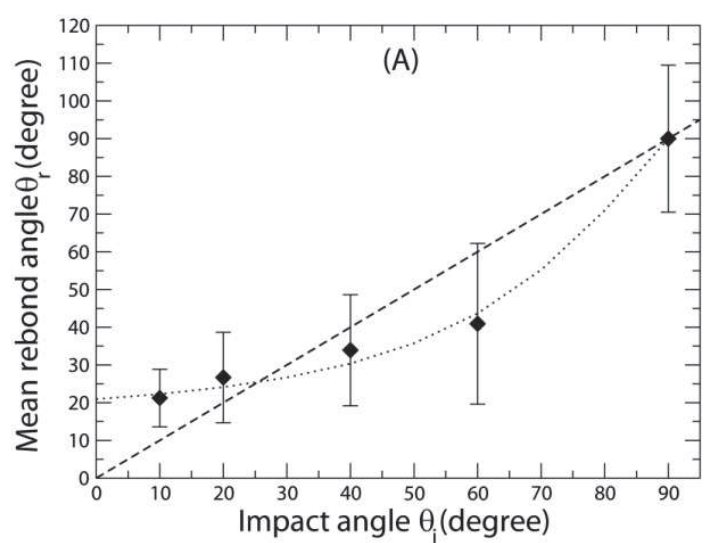




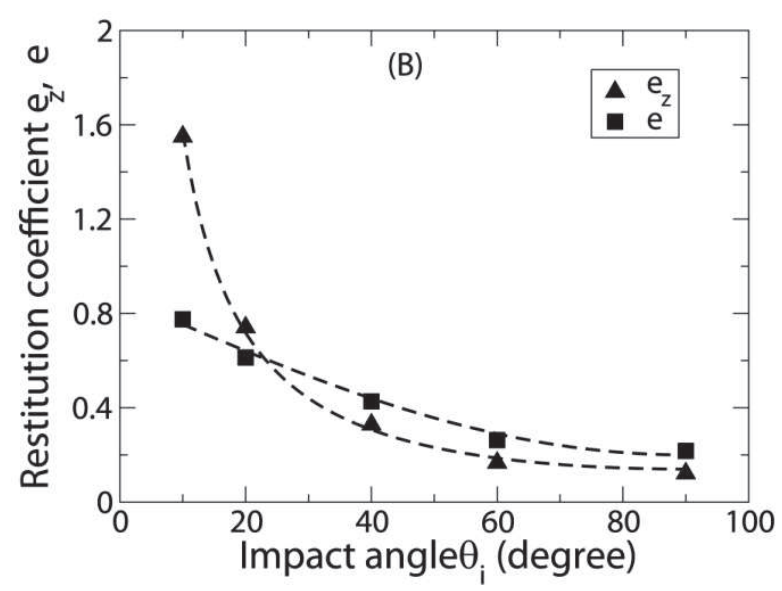

Fig. 6. (A) Model collision experiment with 6-mm particles (Beladjine et al., 2007): mean rebound angle $\theta_{r}$ as a function of the impact angle $\theta_{i}$ for a fixed impact speed $V_{i}=106\left(g D_{p}\right)^{1 / 2}=26 \mathrm{~m} / \mathrm{s}$. The dashed line represents the specular limit (i.e., $\theta_{r}=\theta_{i}$ ). (B) Model collision experiment with 6-mm particles (Beladjine et al., 2007): variation of the average restitution coefficients $e_{z}$ and $e$ as a function of the impact angle $\theta_{i}$ for a fixed impact velocity $V_{i}=106\left(g D_{p}\right)^{1 / 2}=26 \mathrm{~m} / \mathrm{s}$. The dotted lines stand for best fits of the form: $e_{z}=A_{z} / \sin \left(\theta_{i}\right)-B_{z}\left(\right.$ with $A_{z}=0.30$ and $\left.B_{z}=0.15\right)$, and $e=A-B \sin \left(\theta_{i}\right)$ (with $A=0.87$ and $B=0.72$ ).

An important consequence of this is that horizontal momentum of the impacting particle is converted into vertical momentum of the rebound particle. This feature is clearly seen through the vertical restitution coefficient $e_{z}$ characterizing the rebound and defined as $e_{z}=V_{r, z} / V_{i, z}$ (where $V_{r, z}$ and $V_{i, z}$ are, respectively, the vertical components of the rebounding and impacting velocity). As shown in Fig. 6B, $e_{z}$ increases with decreasing 
impact angle and exhibits values $>1$ for impact angle smaller than $20^{\circ}$. This conversion from the horizontal to the vertical direction is fundamental in order to maintain the saltation motion. Indeed, a saltating particle in a steady motion has to reach on average the same height for each of its successive jumps. During the ascending phase of the jump, the saltating particle experiences air drag forces, thus dissipating energy. The energy dissipation in the vertical direction should be balanced by energy gain. This balance is made possible thanks to the momentum conversion during the collision. The physical reason behind this behaviour lies in the roughness or, more exactly, the bumpiness of the bed surface. On a perfectly smooth surface, one expects a specular reflection, while on a bumpy surface one expects a rebound angle greater than the incident angle for grazing collision. Currently we are unable to predict the transition angle from simple arguments, but this critical value is expected to be dependent on the geometrical roughness of the bed surface. For example, if we imagine a collision of a fine particle onto a packing of coarse particles, the critical angle for the transition may be larger because the effective bumpiness of the bed surface (compared to the diameter of the incident particle) is enhanced.

We introduce another restitution coefficient, $e$, defined as the ratio of the rebound speed to that of the impact speed:

$$
e=\frac{\left|V_{r}\right|}{\left|V_{i}\right|} .
$$

The knowledge of both coefficients, $e_{z}$ and $e$, is sufficient to characterize completely the rebound process. As shown in Beladjine et al. 
(2007), both are independent of the impact velocity and are decreasing functions of the impact angle. They are well approximated by the following laws:

$$
\begin{aligned}
& e_{z}=A_{z} /\left(\sin \theta_{i}\right)-B_{z} \\
& e=A \sin \theta_{i}-B
\end{aligned}
$$

$A_{z}, B_{z}, A$, and $B$ are constants, which are expected to depend on the material properties of the particles.

As shown in Crassous et al. (2007), the key material property is the dissipation rate in a binary collision and can be characterized by the normal restitution coefficient $\varepsilon_{\mathrm{n}}$ within a binary collision. The plastic particles used in the model experiments of Beladjine et al. (Beladjine et al., 2007) have a normal restitution coefficient close to that found with glass beads (which are expected to behave as quartz sand grains): $\varepsilon_{n}=0.9$. For these particles the constants in Eqs. (6) and (7) have the following values: $A_{z}=0.30, B_{z}=0.15$, $A=0.87$, and $B=0.72$. One can mention that Werner and Haff (1988) proposed the same type of law for $e_{z}$, deduced from a model collision experiment achieved with sand grain. They found slightly different values but compatible with those of Beladjine et al.: $A_{z}=0.26$ and $B_{z}=0.19$.

\subsection{Splashed particles}


When the incident bead impacts the bed, it does not only rebound but can also eject other beads from the packing. The ejected beads fly off in all directions with a speed that rarely exceeds $10 \%$ of the incident velocity. The experimental results from collision model experiments (Beladjine et al., 2007) show that the number of splashed particles at a given impact angle increases linearly with the impact speed above a critical velocity $\xi_{c}$ (see Fig. 7):

$$
n_{e j}=f_{e j}\left(\theta_{i}\right) \frac{V_{i}-\xi_{c}}{\sqrt{g D_{p}}}
$$

where $f_{e j}\left(\theta_{i}\right)$ is an increasing function of the impact angle, and $\xi_{c}$ is the critical velocity below which no particles are splashed. This critical velocity is roughly independent of the impact angle (Werner and Haff, 1988, Beladjine et al., 2007). Werner and Haff (1988) found that $\xi_{c} \approx 20 \sqrt{g D_{p}}$, whilst Beladjine et al. obtained twice that value.

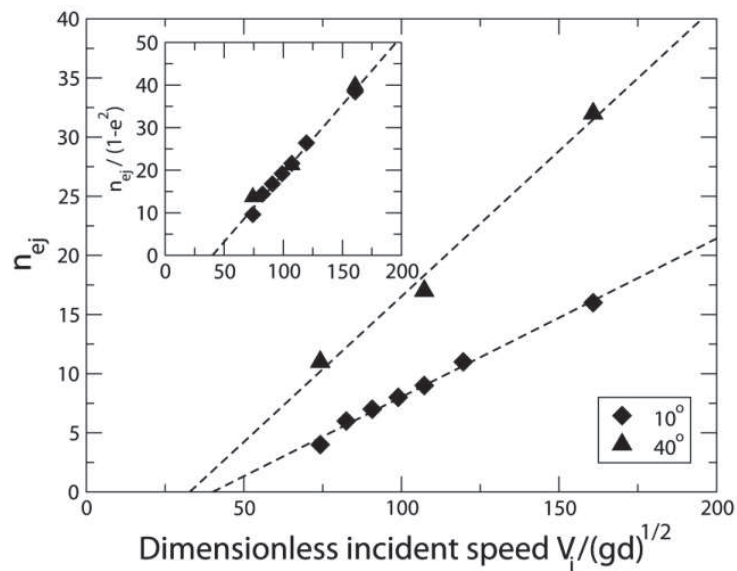


Fig. 7. Model collision experiment with 6-mm particles: the main figure shows mean values of the number of ejected beads versus the impact speed for two different impact angles: $\theta_{i}=10^{\circ}(\diamond)$ and $\theta_{i}=40^{\circ}(\boldsymbol{\Delta})$. Insert shows the collapse of the data when the mean number of ejected beads is renormalized by $\left(1-e^{2}\right)$ (Beladjine et al., 2007)

The linear dependence of the number of splashed particles with the impact velocity indicates that the splash process is predominantly driven by the transport of momentum rather than energy. A collision process based on energy transport would have led to a quadratic dependence of the splashed particles with the impact velocity: $n_{e_{j}} \propto V_{i}^{2} /\left(g D_{p}\right)$.

Several authors proposed a functional form for the dependency of the splashed particles with the impact angle. Werner and Haff (1988) proposed a simple function: $f_{e_{j}} \approx 3 \sin \theta_{i}$ while based on extensive experiments Beladjine et al. (2007) noted that the function $f_{e j}$ is strongly correlated to the energy loss of the impacting particle during the rebound. They indeed found that

$$
f_{e_{j}} \approx 13\left[1-e^{2}\left(\theta_{i}\right)\right] \approx 13\left[1-\left(0.87-0.72 \sin \theta_{i}\right)^{2}\right]
$$

The reason for this fundamental correlation is not completely understood. Based on momentum conversation, we would have expected 
instead that $f_{e j} \sim(1-e)$. This is, however, not what was found based from experiments.

To describe completely the splashed process, one has to specify, in addition to the number of splashed particles, the average take-off velocity of the splashed particles. The model collision experiments show that the average vertical take-off velocity of the splashed particles is independent of the impact angle and weakly sensitive to the impact speed. Therefore the distribution of the vertical take-off velocity is also independent of the impact angle and weakly sensitive to the impact speed. Its main feature is that it exhibits a large tail (Fig. 8)

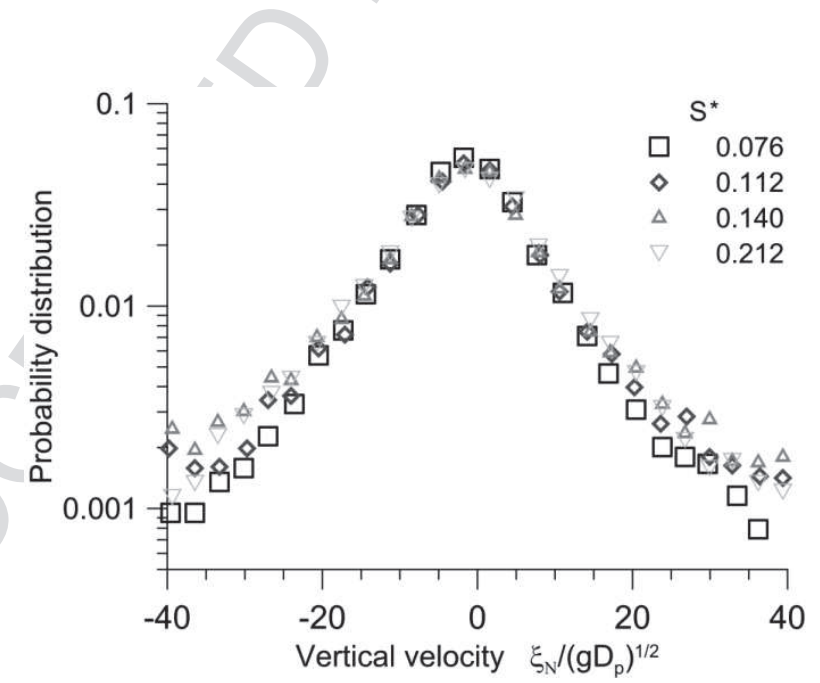

Fig. 8. Wind tunnel observations of the vertical velocity distribution of saltating particles located within the transport layer (at $z=10 D_{p}$ ) immediately above the bed (Ho et al., 2014). Data are shown for different Shields numbers $\left(S^{*}\right)$.

Several distribution laws have been proposed such as the exponential distribution, the $\Gamma$ distribution, and the lognormal distribution that are all 
good candidates to describe the experimental data. Among the distributions, one can mention the Raleigh distribution proposed by Werner and Haff (1988):

$$
P\left(\widetilde{V}_{z}\right)=\frac{\widetilde{V}_{z}}{\sigma^{2}} \exp \left(-\frac{\widetilde{V}_{z}^{2}}{2 \sigma^{2}}\right)
$$

where $\widetilde{V}_{z}=V_{z} / \sqrt{g D_{p}}$ and $\sigma \approx 3.4 \sqrt{g D_{p}}$; and the log-normal distribution suggested by Beladjine et al. (2007):

$$
P\left(\widetilde{V}_{z}\right)=\frac{1}{\sqrt{2 \pi} \sigma\left(\widetilde{V}_{z}-\widetilde{V}_{0}\right)} \exp \left(-\frac{\left\{\ln \left(\widetilde{V}_{z}-\widetilde{V}_{0}\right)-\mu\right\}^{2}}{2 \sigma^{2}}\right)
$$

where $\widetilde{V}_{0}=\sqrt{2}$. The two parameters $\mu$ and $\sigma$ characterize the lognormal distribution: $\sigma \approx 0.78$ while $\mu$ slightly varies with the impact velocity (ranging from 0.25 to 0.55 ) when $V_{i}$ spans from $75 \sqrt{g D_{p}}$ to $160 \sqrt{g D_{p}}$.

The total amplitude of the ejection speed of the splash particles (i.e, $V=\sqrt{V_{x}^{2}+V_{y}^{2}}$ follows exactly the same trend as the vertical ejection speed. The total ejection speed is also almost insensitive to the impact velocity and angle and exhibits a distribution with a large tail.

The last feature of the splashed particles is the angle of take-off. The average take-off angle is found to be independent of the impact speed and 
weakly dependent of the impact angle. It varies from $80^{\circ}$ for grazing impact angles to $90^{\circ}$ for normal impact (Beladjine et al., 2007).

\section{The transport layer}

In the following section we focus on observations of saltation trajectories and grain kinematics in the transport layer. First we consider how slight modification of segmented traps coupled with particle image velocimetry (PIV) and laser Doppler velocimetry (LDV) have added valuable information about saltation dynamics. Then we consider how simple laser sheet illumination has proven a valuable tool to investigate bedform development and movement.

\subsection{The trajectory: information from horizontally segmented traps}

A comprehensive experiment with a primitive horizontally segmented trap was performed at Pismo Beach, CA, USA, by Greeley et al. (1996) and indicated significant downstream variation of grain size and collected mass. Likewise, Horikawa and Shen (1960) used a horizontally segmented trap in a wind tunnel study of particle jump length in saltation. Apart from that little laboratory work involving the use of horizontally segmented traps has been done until the trap shown in Fig. 9 was recently installed across the downstream end of the working section in the wind tunnel in Rennes (Ho et al., 2014). 


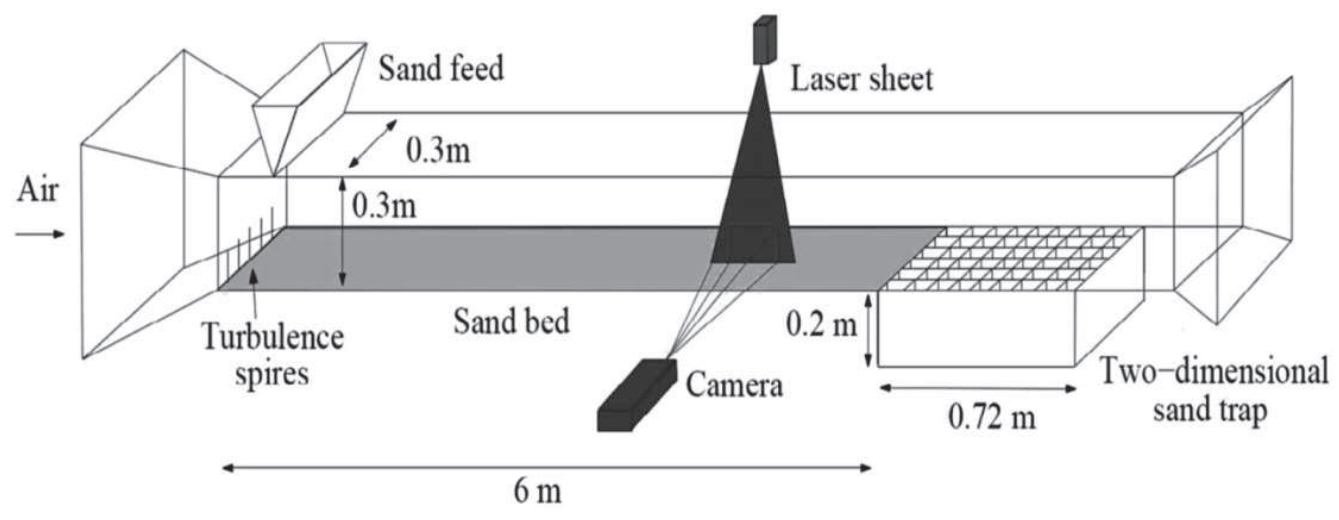

Fig. 9. The horizontally segmented trap in the 6-m-long wind tunnel at University 1, Rennes, France. The spacing between chambers in the twodimensional sand trap is $15 \mathrm{~mm}$. PTV/PIV measurements are made just upwind of the trap.

The collected flux of sand across the central $60 \%$ of the tunnel is uniform, while in the wall-zone the flux gradually decreases to about twothirds of a few $\mathrm{cm}$ from the wall. This corresponds to an effective width of the tunnel of about $90 \%$, which is close to the value reported by Iversen and Rasmussen (1999). A rather similar segmented trap is also installed in the Aarhus wind tunnel, but here it only collects sand across the mid- $60 \%$ of the tunnel over a downstream distance of $60 \mathrm{~cm}$. In the direction of the flow, the first compartment is always $10 \mathrm{~mm}$ wide, but the width of the following compartments varies between 10 and $15 \mathrm{~mm}$. Initially the first 10 compartments were $10 \mathrm{~mm}$ wide followed by $15-\mathrm{mm}$ wide compartments for the remaining distance, but later the setup was changed so that only the 
first compartment is $10 \mathrm{~mm}$ wide while the following compartments are all $15 \mathrm{~mm}$ wide.

Based on initial testing, a reasonable assumption is that no saltating grains are ejected beyond the end of the sand bed $(<3 \%)$ so the data collected in the trap contains accumulated information about the distribution of saltation jump lengths. During steady state mass transport $(q)$, the flux collected in the first chamber of the trap $\left(M_{0}\right)$ represents the vertical saltation flux, i.e., the mass of particles ejected per unit time and area. Let $\mathrm{P}_{\lambda}(\lambda)$ be the distribution of saltation jump length then, according to Ho et al. (2014), the average jump length $\bar{\lambda}$ can be calculated as

$$
\bar{\lambda}=\int_{0}^{\infty} \lambda P(\lambda) d \lambda=\frac{q}{M_{0}}
$$

Ho et al. (2014) used a fine-grained sample $\left(D_{p}=0.23 \mathrm{~mm}\right)$ and a rather coarse-grained sample $\left(D_{p}=0.63 \mathrm{~mm}\right)$, and they observed that although the normalized jump length $(\lambda / d)$ is different for the two samples, no clear variation of $\lambda$ with Shields parameter is observed. Observations of $\lambda$ using the horizontally segmented trap in the Aarhus wind tunnel are weakly sensitive to flow strength, which is also the case for horizontal trap field data (Namikas et al., 2003) for which Ho et al. (2014) have derived the mean jump length in a way similar to that used in the analysis of the Rennes wind tunnel data (Fig. 10A). Notably, in addition to bias caused by rebouncing of grains on the wall-tops between compartments, the 
calculation of $\bar{\lambda}$ is very sensitive to the mass collected in the first chamber where small irregularities in the bed in front of the trap may result in considerable experimental scatter.

Despite the modest variation in jump length observed above, a rather consistent picture emerges when wind tunnel and field data are plotted together (Fig. 10A) with a mean jump length of the order of $60-75 \mathrm{~mm}$. For the sand-size particles investigated above, the mean saltation length is not related to the sand grain size in a simple manner. Instead the analysis made by Ho et al. (2014) on limited experimental data suggested that it depends linearly with the height of the Bagnold focus point, which shows a slight variation with grain size as indicated in section 2 . In the experimental data there is a slight indication that the jump length may actually increase slightly with friction velocity and that a possible reason is suggested by the small increase in sediment catch in the most downwind compartments for high wind speeds, which is present in the data observed by Ho et al. (2014) and in the recent observations in the Aarhus wind tunnel using an intermediate-sized sand sample (Fig. 10B).

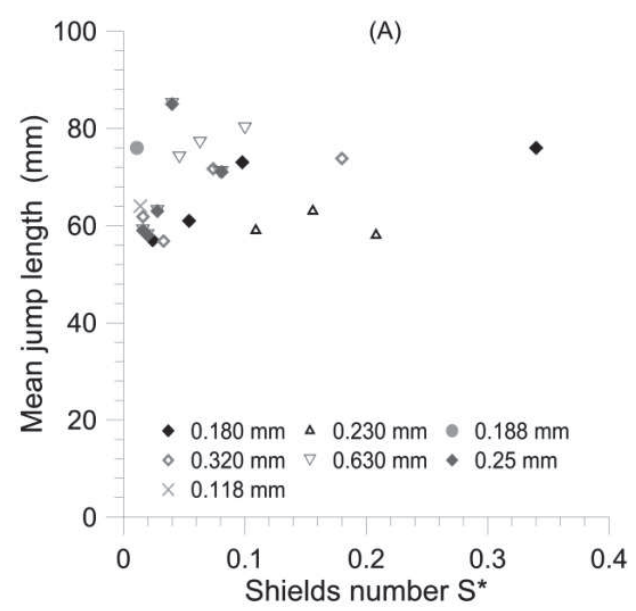




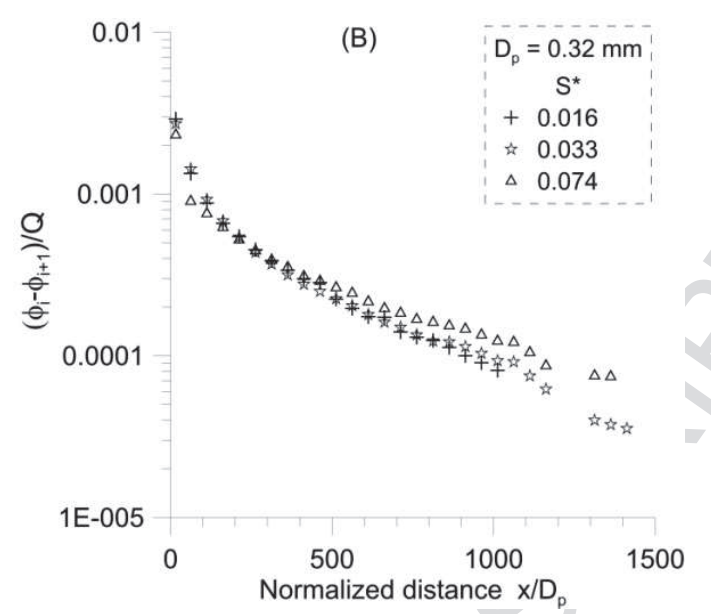

Fig. 10. (A) Mean jump length vs. Shields number for natural sands of different particle size $\left(D_{p}\right)\left(0.118 \mathrm{~mm}<D_{p}<0.63 \mathrm{~mm}\right.$; (B) normalized distribution of the downstream decrease of mass flux collected in trap compartments $\left(\phi_{i}\right)$ at three different Shields numbers $(Q$ is the total mass flow rate).

4.2. The trajectory: information from laser-assisted tracking and velocimetry.

For quantities such as particle concentration, velocity, and trajectory characteristics in the transport layer, the laser light is one of the primary tools in experimental work that has brought recent advances in the field of aeolian dynamics. This is not only the case for sophisticated use of laser light in advanced instrumentations but also for simple setups where laser light has been used in combination with, e.g., photography. Three commonly applied methods are particle tracking velocimetry (PTV), particle imaging velocimetry (PIV) and laser Doppler velocimetry (LDV) - the latter also refered to as laser Doppler anemometry (LDA) (Rasmussen et al., 
2009). In PTV and PIV, a high-powered pulsed laser serves as the light source for generating a vertical laser sheet (Fig. 9). Particles passing within the light sheet are illuminated, and a digital camera is able to capture each light pulse in separate image frames (for a discussion of the sampling strategies we refer to Creyssels et al., 2009). However, what should be pointed out is that in complex particulate flows, which exhibit a large range of particle velocities, the dynamic range of the standard PIV method is often saturated and that severe limitations occur on the measurability of some flows. This is, for example, the case for the flow of saltating particles where great heterogeneity of the particle velocities exists because of the existence of two distinct dynamic populations: the ascending and descending grains. Here grain velocity is underestimated (Creyssels et al., 2009), while such limitations are avoided in the PTV-technique where evaluation of the particle displacement is performed by individual particle tracking, not by means of spatial correlation. In LDV the Doppler shift of two collimated coherent laser beams is used to measure the velocity of a (tracer) particle. As particles move through the fringes of the interfering beams, they reflect light that fluctuates in intensity, the frequency of which is proportional to the component of particle velocity that lies in the plane of two laser beams. For all the laser-based measurement methods, an important advantage is that using optics with a large enough focal length will allow measurements to be made from outside the wind tunnel when part of the side wall is transparent. The PTV allows measurements quite close to the bed, but here reflections from the bed may obscure LDV measurements resulting in unrealistic 
values and low validation rates — at least in the early LDV instruments (Rasmussen and Sørensen, 2008). The beam height of an LDV instrument is typically less than a quarter $\mathrm{mm}$ so it is possible to precisely set the elevation of the measurements. In the direction perpendicular to the flow the crossing between the two beams is slightly larger (mm-scale), depending on the focal length of the optics and whether a beam expander is being used, yet the measuring position is quite well defined. Contrary to this the rate of grains that can be detected is limited by the small measuring volume, and irregularities in the bed combined with the movement of ripples continuously change the local bed elevation. Therefore for the LDV instrument that will not continuously record the position of the bed, we find that it is impossible to acquire good quality data much closer to the bed than 2-3 $\mathrm{mm}$

\subsubsection{The vertical profile of concentration}

For different free stream velocities, Liu and Dong (2004) used PDV data to derive a concentration profile near the downstream end of a $2.5-\mathrm{m}$ long and 0.8-m-wide sand bed composed of sand samples each having a narrow range of grain diameter $D_{p}$. At elevation $z$ they calculated mass flux density $\left(\varphi_{z}=n \rho_{p} \Omega_{p} / A_{L D A}\right)$ normalized with grain momentum $\left(\rho_{p} V_{p z}\right)$ where $n$ is the rate of grains passing the cross-sectional area of the laser $\left(A_{L D A}\right), \rho_{p}$ and $\Omega_{p}$ is particle density and volume, and $V_{p z}$ is grain velocity. Unfortunately they did not measure friction velocities, which prevents a 
thorough comparison with other concentration data. For grains of diameter $0.2-0.3 \mathrm{~mm}$ and free stream velocities of $10,12,14,16$, and $18 \mathrm{~m} / \mathrm{s}$, their concentration profiles are shown in Fig. 11. Zhang et al. (2008) used PTV to measure the concentration profile downstream of a $1-\mathrm{m}$-long and $0.2-\mathrm{m}-$ wide tray with $0.1-0.125 \mathrm{~mm}$ quarts sand. Their concentration measurements are presented in a rather unconventional way as $\mathrm{g} / \mathrm{cm}^{2}$ with little accompanying information of calculation methods. Thus we interpret that the mass is estimated from particles counted at a given increment in elevation normalized with the (planar) area at that elevation, while no volume is considered. Therefore we cannot make a quantitative comparison, but when plotted in Fig. 11 their data show a very different structure than that found in the Liu and Dong data.

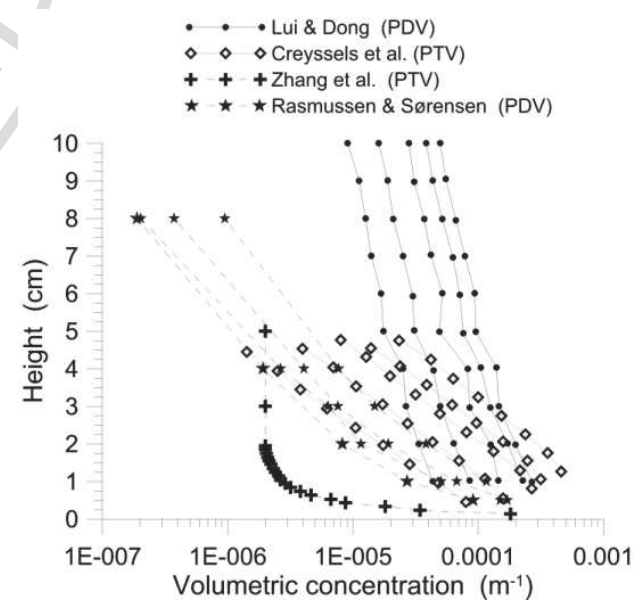

Fig. 11. Compilation of particle concentration data. Profiles are for free stream velocity (Liu and Dong, 2004) and different $u *(0.24,0.32,0.48$, 0.56, $0.67 \mathrm{~m} / \mathrm{s}$, Creyssels et al., 2009; 0.27, 0.38, 0.56, $0.69 \mathrm{~m} / \mathrm{s}$, Rasmussen and Sørensen, 2008). 
Using PTV, measurements of true volume concentration were derived by Creyssels et al. (2009) for 0.242-mm saltating particles in the Aarhus wind tunnel. Profiles are given for friction velocities almost evenly distributed in the interval $0.24-0.69 \mathrm{~m} / \mathrm{s}$. The profiles show a reasonable exponential behaviour, and Creyssels et al. (2009) found that to the first order, the increase of the extrapolated concentration at the bed $\left(v_{0}\right)$ is proportional to the Shields parameter $v_{0}=\beta\left(S^{*}-S_{t}\right)$ with $\beta \approx 0.017$ and $S_{t}$ $\approx 0.009$, where $S_{t}$ is the critical Shields parameter below which saltation cannot be sustained. Reinterpretation of older PDV-measurements of grain speed and transport rate (Rasmussen and Sørensen, 2008) enable us to derive concentration profiles above a bed composed of the same sand sample but using a methodology similar to that used by Liu and Dong (2004). We are aware that besides uncertainty caused by the low number of observed data at the higher elevations $(<50)$, a primary source of uncertainty is associated with the estimation of the effective measurement cross section. For the particular laser instrument used by Rasmussen and Sørensen (2008), the nominal measurement volume is $0.2 \mathrm{~mm}$ high and 4.8 mm wide. However, the grains that have varying shape from pure angular to almost spherical have diameter similar to the height of the measurement volume. Therefore we have used an effective height of $0.6 \mathrm{~mm}$ in this way rather arbitrarily, assuming particles being detected if more than $\sim 20 \%$ of their diameter passes the laser cross section. When the LDV-concentration profiles are plotted in Fig. 11 they are observed to fall within reasonable 
proximity to the PTV data, but the match is rather poor for the larger friction velocities. However, the two sets of data from the Aarhus wind tunnel where the fetch is more than $10 \mathrm{~m}$ long have reasonably similar slope. The profiles measured by Liu and Dong (2004) over a much shorter bed are considerably steeper. This may be expressed in the value of the decey-length $\left(l_{c}\right)$, i.e., the elevation at which the concentration $(v)$ has dropped to $37 \%\left(e^{-1} \times v_{0}\right)$ of the surface value. For the Creyssels et al. (2009) data $l_{c} \approx 10 \mathrm{~mm}$, while it is $30-40 \mathrm{~mm}$ for the Liu and Dong (2004) data. The latter value seems rather large given that on soft beds most of the transport will normally take place below this height (Dúran et al., 2011). Finally, the profiles measured by Zhang et al. (2008) downwind of a very short fetch have no similarity with the rest of the data. This might indicate a long fetch is important for establishing an equilibrium concentration profile in wind tunnel studies.

\subsubsection{The vertical profile of grain speed}

Analysis of high speed movies has been a useful way of acquiring detailed information about the velocity of saltating grains, but in recent years PIV, PTV, and LDV methods (as described in the previous section) have become the common methods. The average horizontal grain velocity measured in a number of experiments using PTV as well as one- or twodimensional LDV instruments are presented in Fig. 12. 


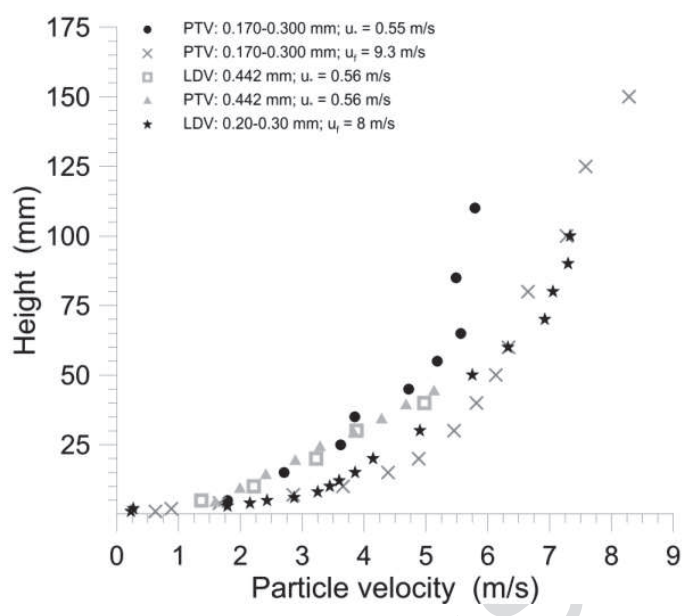

Fig. 12. Vertical profiles of the average horizontal grain speed for different $u *$ and $D_{p}$ (• Kang et al., 2008; (D, \& Creyssels et al., 2009; Dong et al., 2004).

Generally, observations show that up to about $10-15 \mathrm{~mm}$ above the bed the velocity of grains is small and of the order of $0.5-2 \mathrm{~m} / \mathrm{s}$. The data presented in Fig. 12 have been recorded at low or intermediate friction velocities, but observations made by Creyssels et al. (2009) and Kang et al. (2008) for a range of friction velocities or free stream velocities indicate the existence of a focal region between 5 and $10 \mathrm{~mm}$ height with almost constant grain velocity. Contratry to this, Dong et al. (2004) found somewhat higher values below $\sim 5 \mathrm{~mm}$ height. However, their data were recorded using LDV at the end of an only 2.5-m-long test section and their data near the bed show considerable scatter. In addition to the short fetch, LDV-recording close to the bed is difficult as discussed by Rasmussen and Sørensen (2008). The major difference between the data presented by Creyssels et al. (2009) and those by Kang et al. (2008) and Dong et al. 
(2004) is in the velocity-structure between 10 and $50 \mathrm{~mm}$ height. Creyssels et al. (2009) (and one data set presented by Kang et al., 2008) indicate that the velocity increases linearly with height while the remaining data fit closer to an exponential increase. However, the experimental setups differ as the length of test bed used by Creyssels et al. (2009) is from 4 to 6 times longer than the other test beds. Insufficient adaption of the wind profile to an abrupt change in roughness might explain some of the difference. Another influence might stem from the LDV-recording strategy that is based on either acquiring a fixed number of particles (e.g., 5000) or the total number of particles within a fixed time interval (e.g., $30 \mathrm{~s}$ ). When one of the conditions is fulfilled at a given height, recording will continue at the following height. Another uncertainty of data might be that close to the bed the high transport rate results in short sampling times — often $<15 \mathrm{~s}$. Given that wind ripples exist on the bed, then the recordings will represent a particular section on a single ripple. Unfortunately neither Kang et al. (2008) nor Dong et al. (2004) gave information about $u *$ (or Shields parameter) so a closer comparison of results is not possible. Finally, we should note that because grain concentrations above $15-20 \mathrm{~mm}$ are very low, the speed of these grains will only have a minor influence on the average speed regarding the entire saltation layer.

\subsubsection{The vertical profile of flux density}


Given information about grain concentration and velocity, the vertical profile of flux density can be calculated as the product of the two. For low and moderate friction velocities, Creyssels et al. (2009) presented flux density profiles for a sand bed with $D_{\mathrm{p}}=0.442 \mathrm{~mm}$ (Fig. 13).
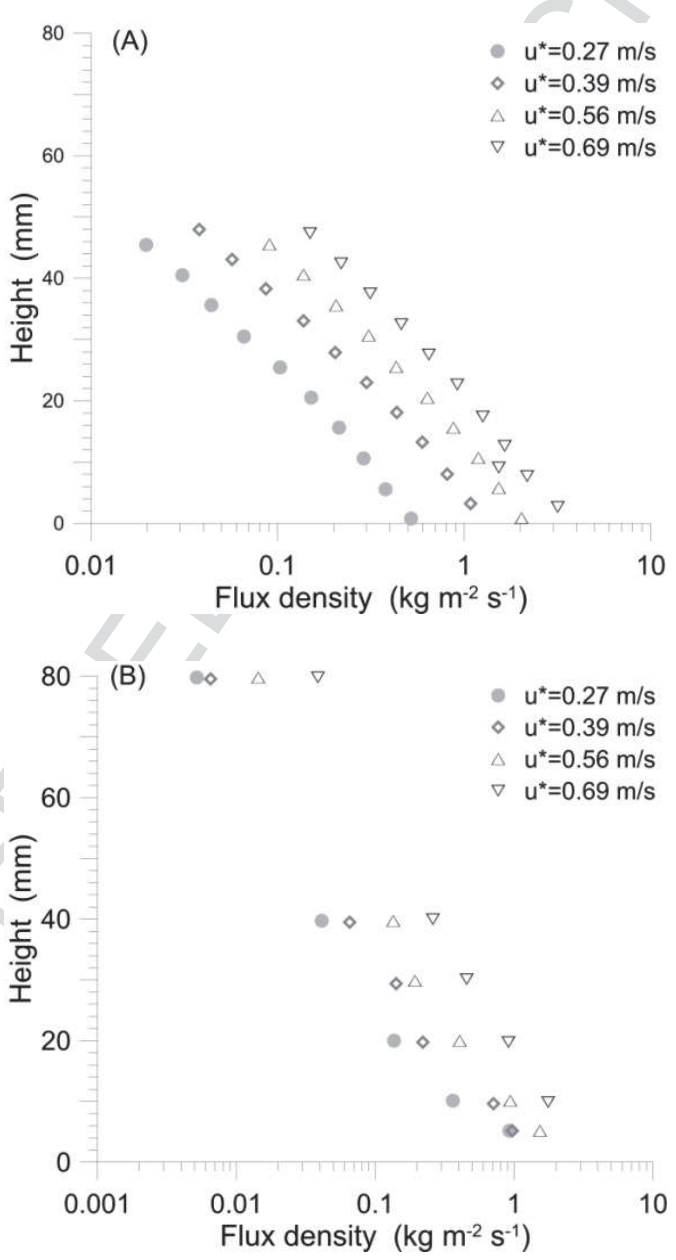

Fig. 13. Vertical profiles of mass flux density $\phi(\mathrm{z})$ : (A) PTV measurements (Creyssels et al., 2009); (B) LDV measurements from the Aarhus wind tunnel $\left(D_{p}=0.242 \mathrm{~mm}\right)$. 
In some experiments where the flux density profile $(\phi(z))$ has been found from LDV measurement data nearest to the bed $\left(\sim 25 \times D_{p}\right)$, it apparently shows a larger increase toward the bottom than given by the exponential dependence (Fig. 13B). If we ignore this, the constant slope in the two figures indicates an exponential decay of flux density with height. When extrapolating the profile to the bed, we find $\phi(0)=\phi_{0}$; and for the data in Fig. 13A, Creyssels et al. (2009) found the characteristic decay length $l_{\phi}$ to $40 \times D_{p}$.

Further analysis of the data in Fig. 13A indicate that for the same sample the flux density profile will collapse to one curve when normalized with the excess Shields number $S^{*} S_{t}$ where $S_{t}$ is the critical Shields number and where scaling with $\sqrt{g D_{p}}$ may additionally account for the influence from grain size where appropriate (Dúran et al., 2011). Based on the data in Fig. 13, we have found the normalized flux density profile for the $0.442-\mathrm{mm}$ sample (Fig. 14).

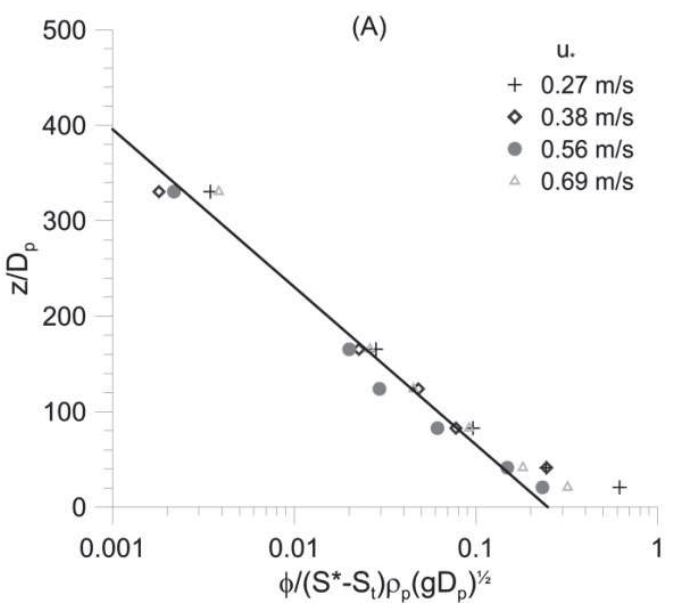






Fig. 14. (A) Normalized flux density profile recorded at four friction velocities (data from Fig. 13B); (B) relative flux densities at four free stream velocities (data from Dong et al., 2006)

For the low and moderate shear stresses in Fig. 14, the collapse of the result when normalized with the Shields parameter indicates that total transport rate is proportional to friction velocity squared as originally suggested by Unger and Haff (1987). Nevertheless quite near the surface the measurements deviate somewhat from the exponential behaviour. In order to compare the results with those obtained in a large wind tunnel but above a short granular bed, we have extracted data from the investigation made by Dong et al. (2006) and plotted these in Fig. 14B. Because no shear stress data can be derived from this setup the Shields parameter cannot be evaluated. Therefore data cannot be normalized in the same manner as in Fig. 14A. Primarily, though, a plot of the flux density normalized with the value at the lowest measurement level will have almost the same slope but shifted along the abscissa axis to a different position. The profiles obtained 
in Fig. 14B at three different free stream velocities are much steeper than those in Fig. 14A, indicating that in the saltation layer the transport reaches higher above the short path than when measured far downstream on the granular bed.

\subsection{Electrification and its effects}

The contact of sand/dust particles with each other during wind-driven transport unavoidably leads to electrification of those particles, typically because of the process known as contact electrification (or sometimes referred to as tribo-electrification). Such electrification can affect aeolian transport in at least two ways, firstly by the generation of electric fields, and secondly by the formation of aggregates or agglomerates because of electrostatic attraction. Although sand grains typically are not noticeably affected by aggregation, the transport of dust is in many cases dominated by the formation and breakup of aggregates, and once deposited dust grains are rarely found in nature as individual single particulates. Despite the importance of electrification and electric field generation in nature and the many studies of such effects, this phenomenon remains poorly understood, in its fundamental physical process and in its effects. Even without a detailed physical understanding of the electrification process, there is general agreement on the order of magnitude of the electrification; and this is sufficient in most cases to quantify the effect of electrification on, for example, entrainment and transport of sand/dust. 
For sand-sized particles (e.g., around $100 \mu \mathrm{m}$ ) in terms of electrical charge per grain, these empirical values correspond to the order of $10^{-14}$ $10^{-12} \mathrm{C} /$ grain, i.e., $10^{5}-10^{7}$ electrons/grain (Schmidt et al., 1999; Gross et al., 2001; Sickafoose et al., 2001; Zheng et al., 2006). For suspended dustsized grains (e.g., 1-10 $\mu \mathrm{m}$ ) electrification of around $10^{-16}-10^{-14} \mathrm{C} /$ grain, i.e. 1000-100,000 electrons/grain, has been observed (Merrison et al., 2004, 2012). These values are in reasonably good agreement with a proposed surface electrification limit (surface charge density) of the order of 0.1 $\mathrm{mC} / \mathrm{m}^{2}$ (Poppe et al., 2000); this has been supported by other work (Lowell, 1986; Perko, 2002; Merrison et al., 2004). Lower values of dust electrification are, however, often measured owing to the electrostatic aggregation of dust that discharges (de-electrifies) suspended dust, especially when in high concentrations and after long suspension times.

Efforts are ongoing to establish the size dependence of electrification; however, one extremely important aspect of contact electrification is that it is seen to preferentially electrify large grains positively with respect to smaller grains during interaction (Lacks and Levandovsky, 2007; Lacks et al., 2008; Kok and Lacks, 2009). The subsequent separation of larger sand grains from suspended dust grains is then seen as a mechanism for electric field generation (Jackson and Farrell, 2006). This is illustrated most clearly during volcanic eruptions where lightening (electrical discharge) is often seen within dust/ash clouds as a result of such electric field generation.

There has been extensive experimental and theoretical modelling of the effects of electric fields upon sand transport with the assumption that the 
surface is electrically conductive (Kok and Renno, 2006). In this case the threshold for entrainment or detachment is seen to fall (Kok and Renno, 2008a,b) and the transport rate seen to rise (Rasmussen et al., 2009). However in the case of known extraterrestrial planets and also many terrestrial environments, the planetary surface may not be considered to be conductive and may in fact be a good insulator. In this case the effect of an electric field is to inhibit entrainment and enhance particle aggregation (dielectric attraction). This has been demonstrated experimentally (HolsteinRathlou et al., 2012; Merrison 2012). A simple model based upon Bagnold's (semiempirical) sand transport model and modifying it with the inclusion of a vertical electric field stress term has successfully reproduced the experimentally observed modification of the threshold and transport rate for saltation in a laboratory sand bed while applying an electric field (Rasmussen et al., 2009). It involves modifying the wind induced lift stress at threshold with the addition of an electric field-induced term — which for a conducting surface is $\tau_{E}=+1 / 2 \varepsilon_{0} E^{2}$, where $E$ is the electric field strength at the surface, and $\varepsilon_{0}$ is the permittivity of free space. In the case of an insulating surface, it becomes $\tau_{E}=-F_{\infty} \varepsilon_{0} E^{2} r^{2}$ (Stoy, 1995); here $r$ is the grain radius and $F_{\infty} \approx 3$ for a dielectric material (such as glass/silicate) with a susceptibility of around 3. Note that this force is negative, i.e., attractive toward the surface. Unfortunately the complexity expected within a natural saltating bed in terms of electrification and electric field generation may make it difficult to predict or even identify the net effect. 


\subsection{Temporal and spatial variation of bed texture}

\subsubsection{Observation methods}

The use of erosion pins is a well-tested method to acquire information about temporal changes of a granular bed. In a wind tunnel, Andreotti et al. (2010) used this method to follow changes in the bed elevation along the tunnel axis, and in this way estimated the sediment transport saturation length $\left(l_{\text {sat }}\right.$, see section 2.3). Low-angle lighting and a meter stick is another simple way by which detailed information about ripple spacing has been acquired over sand beds composed of different-sized sands (Walker, 1981). Elaborate studies of bedform morphology and its temporal changes require two-dimensional resolution; and here high precision photogrammetry has been successfully used to study the development of, for example, wind ripples (Seppälä and Lindé, 1978). Until recently the analysis of photographic or photogrammetric recordings has been fairly slow and cumbersome as compared to digital measurement using precision laser scanner tools. In recent years this has been used to characterize the structure and stability of bed texture (McKenna Neuman et al., 2012), but the recent development of new digital techniques for three-dimensional mapping such as the structure from motion principle (Westoby et al., 2012) may change this.

Nevertheless very useful information may also be acquired from using a much simpler laser-based method when combining a laser sheet with a 
camera positioned with its axis at an angle to the plane of the laser. The camera may be placed vertically above the bed looking from an acute angle through a transparent wall of the wind tunnel or vice versa, depending on the actual laboratory conditions. When the bed is completely horizontal, the footprint of the laser is a straight line below the camera while positive or negative elevation deflects the laser light to one or the opposite side (Fig. 15). When calibrated carefully, quite small changes in bed elevation may be observed by comparing images recorded before and after the change. Andreotti et al. (2006) used laser profiling to measure stages of aeolian ripple formation on a rather fine sand $\left(D_{p}=0.12 \mathrm{~mm}\right)$ in a 4.5 -m-long wind tunnel ( $1 \mathrm{~m}$ wide, $0.5 \mathrm{~m}$ high), while a similar method has recently been used in the Aarhus wind tunnel to acquire some information on the longterm variation of ripple geometry (Fig. 15).
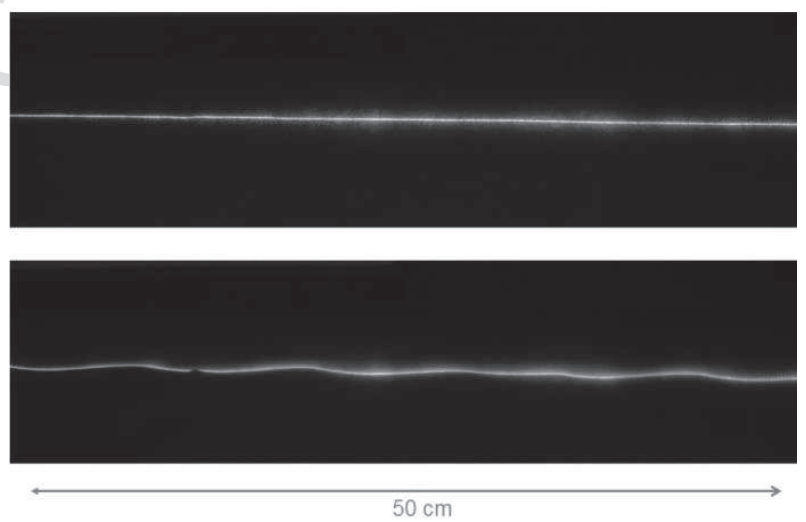

Fig. 15. Vertical profile view of a laser-trace on a sand bed $\left(D_{p}=0.18 \mathrm{~mm}\right)$ in the Aarhus wind tunnel. Upper: the flat bed at the start of the experiment; Lower: the same section when exposed to 30 -min wind flow $(u *=0.49$ $\mathrm{m} / \mathrm{s}$ ). The laser is placed vertically above the bed with the sheet aligned 
along the tunnel axis. The camera is placed in front of the tunnel so that the camera focuses on the laser trace at an angle of near $20^{\circ}$ to the (horizontal) bed. Ripple amplitude is $\sim 2.5 \mathrm{~mm}$.

\subsubsection{Some observations of ripple spacing}

Traditionally, a distinction is made between impact ripples (which form in fine unimodal sands and have spacing up to $0.2 \mathrm{~m}$ ); and megaripples (which form in coarse bimodal sand and have larger spacing; Ellwood et al., 1975), but in the following we shall consider impact ripples only.

A comprehensive study of ripple spacing $(\Lambda)$ and height $(h)$ was made in a 30-m-long wind tunnel at MIT (Walker, 1981) using sand samples of different size $\left(D_{p}\right)$ and sorting. However, the following discussion will consider ripple spacing only. From Walker's data for well-sorted samples, we have calculated dimensionless ripple spacing $\left(\Lambda / D_{p}\right)$ and normalized friction velocity $(u * / u * t)$ in the same manner as Andreotti et al. (2006). Because Walker (1981) did not systematically observe $u *$, this has been estimated using data given by Iversen and White (1982). Obviously the estimated $u_{*}$ and $u *$-values are somewhat uncertain since for the 0.25 and $0.78 \mathrm{~mm}$ size groups there is one observation of $\Lambda$ for $u * / u_{*}<1$. However, the influence of such error is a minor displacement of the data points in Fig. 16 parallel to the $x$-axis that will not influence the general picture shown by Walker's (1981) data. Ripple spacing increases moderately with $u *$ from 
threshold $\left(u_{*}\right)$ to the critical value $\left(u_{* f b}\right)$ at which ripples disappear and a flat bed evolves (Fig. 16). Furthermore, $\Lambda / D_{p}$ depends inversely on $D_{p}$ - the finer the material the larger the spacing.

For the transition to the (upper) flat-bed regime, Walker observed a minimum of $u_{* f b} \approx 0.6-0.7 \mathrm{~m} / \mathrm{s}$ for $D_{p} \approx 0.3-0.4 \mathrm{~mm}$; while for the finest size group he observed a substantial increase in $u_{* f b}$ to almost $1 \mathrm{~m} / \mathrm{s}$.



Fig. 16. Ripple spacing versus friction velocity for uniform sand samples having different particle diameter $D_{p}$. Data for sizes $0.20,0.25,0.32,0.40$, $0.78 \mathrm{~mm}$ are from Walker (1981); data for the 0.18 sample are recent measurements in the Aarhus wind tunnel; while the $0.12 \mathrm{~mm}$ data are from Andreotti et al. (2006). 
The temporal evolution of the ripple pattern on a bed composed of fine sand $\left(D_{p}=0.12 \mathrm{~mm}\right)$ was also investigated by Andreotti et al. (2006). They identified three regimes (Fig. 17A): appearance of an initial wavelength, coarsening of the pattern, and finally after some time (typically $10 \mathrm{~min}$ ) saturation of the ripples so that (statistically) ripples will essentially propagate without changing shape and amplitude anymore.


Fig. 17. (A) Temporal development of the ripple pattern on a 1-m section ( $x$ axis) of a sand bed $\left(D_{p}=0.12 \mathrm{~mm}\right)$. Time ( $y$-axis) is given in minutes (Andreotti et al., 2006). (B) Temporal development of ripple wavelength on 
a bed composed of quartz sand $D_{p}=0.180 \mathrm{~mm}$. Time in minutes on $x$-axis and ripple wave length (spacing) on $y$-axis.

In the Aarhus wind tunnel the development of ripple wave length for a bed composed of $0.180 \mathrm{~mm}$ quartz sand was studied at three different friction velocities using an $\sim 50$-cm-long laser trace (Fig. 15B). Because of the relative short trace, spatial variation of the ripple pattern as it travels past the test section will inevitably result in some fluctuation in the observed wave length. Occasionally the merging of two ripples crests into one or the formation of a new ripple within the existing pattern will result in apparent fluctuation in the wavelength, which would have been less pronounced with a longer test trace. At the lowest friction velocity $(0.29 \mathrm{~m} / \mathrm{s})$ it is possible that a final wave length has not been achieved after $60 \mathrm{~min}$, whereas for the highest friction velocity $(0.58 \mathrm{~m} / \mathrm{s})$ a steady state may be reached after only a little more than $10 \mathrm{~min}$. For the intermediate friction velocity $\left(u_{*}=0.42\right.$ $\mathrm{m} / \mathrm{s}$ ) the steady state is reached after about $20 \mathrm{~min}$. Apparently, $\Lambda / D_{p}$ depends moderately on friction velocity as observed by Walker (1981) for the fine sample, although (as expected) values are slightly higher for the 0.18-mm Aarhus sample than for Walker's 0.20 -mm sample. Similarly field observations made by Sharp (1963) and re-interpreted by Andreotti et al. (2006) showed a modest increase of $\Lambda / D_{p}$ with $u * / u_{*}$. Contrary to this, the wind tunnel data presented for the $0.12-\mathrm{mm}$ sand sample investigated by Andreotti et al. (2006) indicate a fairly strong linear increase with friction velocity (Fig. 16). Andreotti et al. (2006) used a wind tunnel with a 4-m- 
long test section, but whether this (at least partly) may explain some of the deviation from the other samples or whether this is entirely a result of the small $D_{p}$ we are unable to explain. For completeness we should mention that data from the laboratory experiment made by Seppälä and Lindé (1978) have been excluded from the analysis above as their sand sample has a very broad size distribution.

\section{Planetary environment simulators}

\subsection{Observations of aeolian sediment transport in the solar system}

It is a challenge to apply conventional semiempirical models of aeolian transport (which have been developed specifically for terrestrial application) to other planetary environments such as Mars or Titan where most physical parameters are significantly different from those of Earth (i.e. density, viscosity, temperature, gravity, humidity, etc.). This challenge, however, may help to drive the development of new models that have a broader physical basis and may thereby also contribute to improving terrestrial transport theories. Four bodies in our solar system have a significant atmosphere and an accessible (erodible) surface which can then be susceptible to aeolian activity: Mars, Earth, Venus, and Saturn's moon Titan (Bourke et al., 2010; Zimbelman et al., 2013; Lorenz and Zimbelman, 2014). 


\subsection{Laboratory simulators}

The aim of laboratory-based studies in planetology is to complement observational investigations by attempting to recreate extreme/extraterrestrial conditions in a controlled way in order to study phenomena in detail and to compare the findings with current models and/or to those seen in nature. A planetary (or environmental) simulator typically attempts to control one or more environmental parameter such as temperature, pressure/fluid density, or composition. In addition, the study of aeolian transport requires some form of wind tunnel where wind conditions can be recreated.

Environmental wind tunnels are rare, especially in the study of aeolian processes or granular transport. The NASA Ames MARSWIT (Mars Surface Wind Tunnel, CA, USA) is an open-circuit, low pressure wind tunnel that has been used to study sand transport at low pressure, specifically quantifying the threshold wind speed for saltation. In addition to this large facility, a much smaller (Venus) wind tunnel allows studies under high pressure conditions. The studies made in these facilities are the basis for the conventional wisdom regarding sand transport on Mars, Venus, and Titan.

The airflow in the MARSWIT facility is generated by a high pressure nozzle ejector system, the total length is $13 \mathrm{~m}$ with a main test section of 1.2 by $0.9 \mathrm{~m}$ and is housed in a $4000-\mathrm{m}^{3}$ low-pressure chamber, which can operate at pressures down to $\sim 3.8 \mathrm{mbar}$ and wind speeds of $20-180 \mathrm{~m} / \mathrm{s}$ (at 
low pressure) (White, 1981; Greeley and Iversen, 1985). Limitations of the system are that the wind speed is not independent of the chamber pressure and that low wind speeds at low pressure are problematic. Additionally this system is not able to control temperature and is not well suited to dust entrainment/transport study.

Environmental (cooled) wind tunnels have been used occasionally in studies of snow transport, often involving processes of electrification that are relevant to the generation of electrical thunderstorms and lightening (Maeno et al., 1985; Schmidt et al., 1999). In the case of the Aarhus environmental wind tunnel facilities, a fully hermetic, recirculating wind tunnel design has been adopted that allows for control of temperature, pressure, composition, and wind flow and allows for the study of suspended aerosol particles (e.g., dust) (Merrison et al., 2008; Holstein-Rathlou et al., 2012). Because of geometrical constraints this requires compromises to be made with respect to flow speed and uniformity but has been extensively used for wind driven dust and for sand-transport studies. The wind tunnel simulator consists of an environmental (thermal-vacuum) chamber within which a recirculating wind tunnel is housed (Fig. 18). The wind is generated by a set of two fans that draw flow down the $2 \mathrm{~m} \times 1 \mathrm{~m}$ tunnel section and return it above and below. The test section can be fully removed for access. Wind speeds in the range of 1 to $25 \mathrm{~m} / \mathrm{s}$ have been demonstrated under low pressure conditions. Cooling is achieved by a novel liquid nitrogen flow system that has achieved temperatures below $-150^{\circ} \mathrm{C}$ within the test section. The inner chamber is thermally isolated from the vacuum chamber. A 
server-based control system provides control over wind flow, temperature, pressure, lighting, etc., but also acts as a data logger.



Fig. 18. (A) Photograph of the AWTSII environmental chamber with modified flow-enhancement section with reduced cross section. (B) A schematic of the chamber construction.

Sensing is a vital part of achieving a controlled and reproducible environment as well as performing reliable experiments. Various sensor 
systems are employed for wind flow, dust suspension (concentration), pressure, temperature, and humidity. Further details of the design and technology employed in this facility are presented elsewhere as well as discussion of previous research programs (Holstein-Rathlou et al., 2014). The most recent developments (modifications) and current/ongoing research however will be discussed here with emphasis on those relevant to aeolian/sediment transport.

\subsection{Settling and detachment studies}

The aerodynamic drag upon an aerosol particle is a fundamental parameter when studying the dynamic interaction of fluid and dust. This can be quantified by measuring the free fall settling velocity. The pioneering work of Millikan around the 1920s led to the conventional semi-empirical theory (Ishida, 1923). Unfortunately few experimental studies have been performed since this time and it has been demonstrated that for aerosols with extremely low Reynolds number or Knudsen numbers approaching or greater than 1 the standard Cunningham correction (or Slip factor correction) is highly inaccurate and the three empirical parameters are not universal, for example dependent upon composition (Rader, 1990). There is therefore a need for a less empirical and more predictive theory to describe the behaviour of fine dust in the upper levels of planetary atmospheres i.e., low pressure (Zhigang and Wang, 2003). 
Given knowledge of the amount of turbulence in the atmosphere settling velocities can directly give information about the suspension time and size distribution as a function of height (and maximum height) for a particular aerosol component. This has motivated an extensive series of experiments in which the settling velocities of size selected $(0.25-40 \mu \mathrm{m})$ spherical silicate particles are measured as a function of pressure (1-30 mbar) in different gases. Here small amounts (around 10mg) of the glass spheres are aerosolized (using an over pressure gas flow system) into the environmental chamber and the settling velocity of individual grains measured using a Laser Doppler Anemometer (Fig. 19).

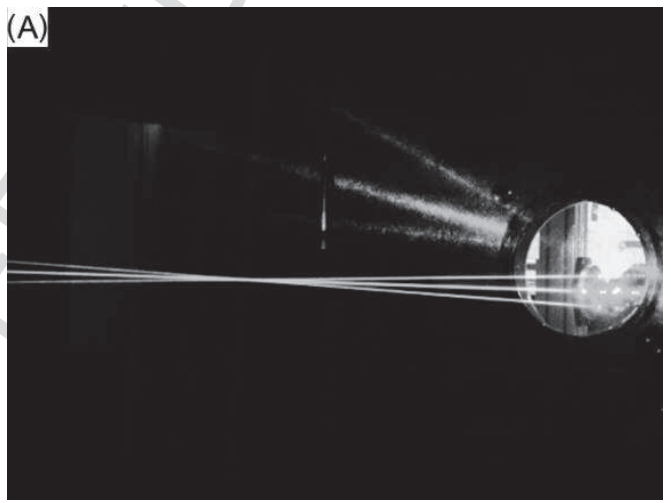

(B)

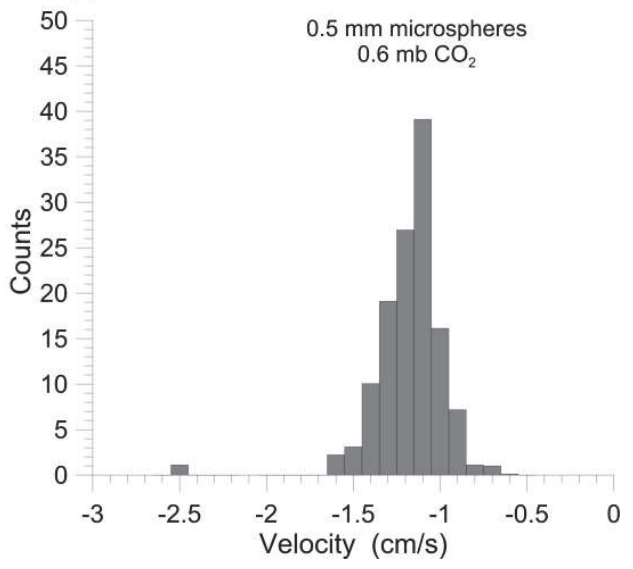


Fig. 19. (A) Laser Doppler anemometer system illuminating aerosolized silica spheres inside the AWTSII environmental chamber. (B) A collected settling velocity measurement series.

This is the first stage in a research program in which the dynamics of suspended particle-gas interactions are to be quantified in detail. This work has direct relevance to the behaviour of aerosols in the atmospheres of a wide range of different planets and it complements similar work studying settling rates of larger (sand/pebble sized) grains in a vertical wind tunnel facility where the effects of morphology have been studied (Bagheri et al., 2014). Here again the conventional theory appears incomplete and new approaches are suggested. Although there is now qualitative agreement in the entrainment process responsible for Aeolian dust transport on Mars details of the dust aggregate detachment, breakup and lifting still need to be studied as well as details of the entrainment rates and effects such as turbulence. Studies have begun within the Aarhus environmental wind tunnel specifically of the dependence on deposited dust depth (structure), dust type, turbulence and wind speed. This again has direct relevance to observation and modelling of dust transport on Mars as well as more generally for Aeolian planetary studies. Qualitative results already indicate that thin dust layers (of the order of 1 monolayer) require significantly higher wind shear stress for removal than thicker layers, supporting the dust-aggregate theorem. 
As discussed in section 2 the saltation threshold has been studied in the laboratory under both terrestrial and Martian conditions (Greeley and Iversen, 1985). In addition sand detachment studies have also been performed (Merrison et al., 2007). There are inconsistencies in the measured Aeolian detachment threshold (typically measured at lower density) and measurements of the saltation threshold under terrestrial conditions. Specifically for larger grains $(>100 \mu \mathrm{m})$ the expected linear dependence upon particle size seen for saltation becomes independent of size for detachment. It is unclear as to whether this inconsistency is due to a difference in the processes of saltation and detachment or a pressure related effect. An incidental observation here is that it is typical that sporadic transport of sand (creep, rolling, rocking) is observed below the threshold for saltation.

The detailed dynamics of saltation (hop length, height, trajectories, transport rates, etc.) have yet to be studied at low atmospheric density relevant to the Martian environment. Such studies have now been started in the Aarhus environmental wind tunnel with the use of a modified crosssection reduction stage in which higher wind speeds (shear stress) can be achieved over a broad pressure range (10 - 1000 mbar).

\subsection{Planetary aeolian environments}

\subsubsection{Venus}


Because of obscuring clouds little detailed/high resolution imaging of the surface of Venus exists apart from synthetic aperture radar (SAR) data. However, there is general agreement that the surface is made up of volcanic material following a resurfacing event that occurred around $500 \mathrm{My}$ ago and that relatively fine granular material is present at the surface. Owing to low wind speeds, no intense aeolian activity seems to appear, despite the high fluid density at the surface. Only two relatively small regions show direct evidence of sand dune formation though in many areas there is evidence for wind streaks (Greeley et al., 1997).

\subsubsection{Titan}

In many ways this moon is the most Earth-like planetary body, despite its cryogenically low surface temperature of around $90 \mathrm{~K}$. Apparently Titan has active and widespread aeolian activity with extensive dune fields (Lorenz and Radebaugh, 2009). The sand here is assumed to consist of a mixture of water ice and organics. Titan has extensive lake and river systems that evaporate, form clouds, and generate precipitation (rain). The presence of flowing liquid and the associated erosion makes it similar to Earth; however, the liquid is mostly methane with impurities of ethane (Bourke et al., 2010; Lorenz and Zimbelman, 2014).

Although the dunes on Titan have been studied from orbit (Cassini mission), no laboratory experiments have attempted to recreate the duneforming process, and details of the saltation process are speculative. With 
the combination of low gravity, high fluid density, low temperature, and exotic (low viscosity and low density) materials, the processes of aeolian transport on Titan would be extremely interesting and challenging to reproduce in the laboratory — firstly to better understand the sedimentary cycles on Titan and secondly to verify atmospheric circulation models.

\subsubsection{Mars}

This planet has been studied (mapped) in great detail from orbit and with the use of landers/rovers, and abundant and extensive dune systems (of many varieties) similar in morphology/scale to terrestrial examples have been observed (e.g., Bridges et al., 2007; Sullivan et al., 2008). The dunes are typically seen to be inactive at present. However, recently rare and sporadic sand transport has been observed in so called dark dunes (Silvestro et al., 2010; Bridges et al., 2012b)

Unlike sand, the transport of dust is widespread, extensive, and seasonal on Mars. It is observed ubiquitously from the surface and from orbit. A detailed comparison of the transport of sand and dust on Mars and Earth will be made in section 5.5 .

\subsubsection{Giant planets - e.g., Saturn, Jupiter, Neptune, Uranus}

These planets can be considered as having extremely deep atmospheres and with no accessible surface. Generally the atmospheric density (pressure) and 
temperature increase with depth (below the exosphere) in a similar way to Earth and with increasing concentrations and differing types of aerosols (suspended particulates), such clouds thus obscure deep atmosphere observation. The study of aerosol transport (turbulent suspension and gravitational settling) as well processes of precipitation, evaporation, etc. are of direct relevance to the understanding of these planets. Therefore despite not having a solid surface some aspects of wind-driven sediment transport can be applied to these environments.

\subsection{Dust and sand transport on Mars}

There are differences in the physical behaviour between sand and dust (silt) because the dominant forces are different. In the case of sand the effects of fluid drag are balanced predominantly by gravitational and inertial effects, whereas in the case of finer dust grains adhesive/cohesive forces become dominant. In the conventional model of aeolian entrainment, we would assume that (individual) dust grains are adhered strongly to the surface and that therefore are extremely difficult to remove by wind shear (Greeley and Iversen, 1985; Shao and Lu, 2000). Dust entrainment (terrestrially) is generally assumed to occur as a secondary process after the onset of saltation, in which case saltating sand grains through impact entrain dust grains (Greeley, 2002). On Mars however, dust entrainment is seen at wind speeds significantly below the threshold for sand entrainment (Holstein-Rathlou et al., 2010). Based on combined laboratory studies 
(Merrison et al., 2007) and observations from Mars (Sullivan et al., 2008) it has been deduced that dust transport on Mars occurs through the formation of large (sand-sized, low density) dust aggregates/agglomerates that during the entrainment process breakup and liberate suspended dust particulates.

Two (independent) reliable wind speed data sets have been obtained from the surface of Mars. They agree reasonably well and give a reasonably reliable determination for the wind speed for which dust transport begins, i.e., around $15 \mathrm{~m} / \mathrm{s}$ measured at around $1.5 \mathrm{~m}$ height (Holstein-Rathlou et al., 2010). Based on estimates of the surface roughness determination of the surface, shear stress could then be made giving a value of around $0.02 \mathrm{~Pa}$. This agrees well with environmental wind tunnel measurements and the model for dust transport involving dust aggregate formation/breakup. It additionally agrees reasonably with values used in global circulation models ( $\left.\tau_{t h} \sim 0.01 \mathrm{~Pa}\right)$ (e.g., Mulholland et al., 2013; Ayoub et al., 2014).

Two common types of dust entrainment phenomena exist: one is referred to as a local dust storm and is associated with localized high wind speeds typically associated with seasonal effects (Kahn et al., 1992). On a smaller scale, solar heating can generate 'dust devils', these are warm core vortices that again are associated with elevated wind speeds sufficient to entrain dust. Crude estimates of the contribution in terms of entrained dust mass have shown that comparable amounts of dust are suspended through both of these phenomena (Balme and Greeley, 2006). The magnitude of dust transport is of the order of 1 billion tons/y through the Martian atmosphere, which is comparable to dust transport on Earth (Moulin et al., 1997). 
In order to improve our understanding of Martian dust transport several crucial sets of data are required. Observationally there lacks direct measurement of suspended dust concentrations and size determination (Lemmon et al., 2004). Experimentally there lacks laboratory studies of dust removal rates and details of the entrainment process. Occasionally dust storms occur on a global scale and their occurrence and nature are as yet poorly understood (e.g., Arvidson et al., 1983; Greeley and Iversen, 1985; Kahn et al., 1992; Balme and Greeley, 2006; Bridges et al., 2007).

The highest measured wind gusts observed at the surface of Mars (of around $25 \mathrm{~m} / \mathrm{s}$ ) are within $20 \%$ of the expected threshold for sand grain entrainment based on wind tunnel simulations and detachment models (Arvidson et al., 1983; Merrison et al., 2007). This is supported observationally for example in basaltic sand ripples at Eagle Crater (see Yizhaq et al., 2014). The sustained and relatively intense transport of sand observed in the so-called dark dunes (thought to be basaltic sand) is however surprising and some theoretical/modelling groups have proposed different dynamics of the splash and height distribution for saltation on Mars as a result of combined effects of reduced gravity and fluid density (Almeida et al., 2008). This has yet to be supported by experiment or direct observation. The relatively dark tone is likely to be as a result of active saltation causing removal of the fine light-toned dust that otherwise covers the Martian surface materials. This fine reddish dust is likely to be an erosion product that has been mineralogically altered (oxidized) during saltation of sand (Merrison et al., 2010). 


\section{Discussion and conclusion}

From a certain threshold of shear stress at which grains start to move on a flat bed we observe the collective organization of grain movement and bed texture during which ripples evolve and after some time move downwind in a steady pattern. This is the condition of the splash regime where saturated saltation is (primarily) governed by the physics of the splash. Beyond a certain high shear stress, the bed becomes flat (upper flat bed regime). Here conditions are difficult to study and poorly understood and this regime is not considered in the present work. The splash regime is where the majority of laboratory investigations have been mad; , and yet due to different scaling between flow in existing laboratory facilities and in the atmospheric boundary layer, the dynamic range of laboratory flow is strongly limited so that full similarity between laboratory and Nature cannot be obtained and allow studies of (for instance) coherent flow features such as streamers (Bauer et al., 2013).

Even without saltation, the shallow equilibrium boundary layer in the laboratory complicates unbiased derivation of the bed shear stress (friction velocity) when this is made from the vertical gradient of the horizontal speed. Therefore sets of roughness arrays and turbulence spires - either in combination or separately — are now commonly used in wind tunnel studies. In this way it is attempted to match the boundary layer to the dynamics of the downstream granular bed (Iversen and Rasmussen, 1999; 
McKenna Neuman, 2004; Kang et al., 2008; Ho et al., 2014). In some saltation studies performed in (low-height) wind tunnels, a correction for the horizontal pressure gradient seems useful for reducing bias in friction velocity (e.g., Rasmussen et al., 1996). Theoretical reasoning indicate that also in wind tunnels with a larger cross-sectional area such pressure-induced influences may seriously bias results if not taken into account, so this is an issue that deserves more clarification.

The wind tunnel investigations that have been considered in the present work may be divided into two major groups depending on the length of the granular bed used in the study. The one group comprises studies made on a downwind section of a long, granular bed extending throughout the working section (e.g., Bagnold, 1936; Shao and Raupach, 1992; McKenna Neuman and Nickling, 1994; Butterfield, 1999; Iversen and Rasmussen, 1999; Bauer et al., 2004; Liu and Dong, 2004; Creyssels et al., 2009; Ho et al., 2014). These tunnels usually have a short section with boundary layer adaption over fixed roughness, before the transition to the granular bed. The other group of experiments use an entry section that after the boundary layer adaption may have a flat, smooth bed before a short, granular test patch. This patch is typically 1-4 m long, often covering only a limited part of the total working area in the tunnel (e.g., Liu and Dong, 2004; Dong et al., 2006; Zhang et al., 2008 ).

The results from these two groups are difficult to compare quantitatively. A reliable bed shear stress can be estimated above the long granular bed with equilibrium saltation; but this is impossible for the short 
beds where the abrupt roughness change at the upwind end of the granular patch results in transitional flow conditions (Brutsaert, 1982; White, 1991). Because a proper bed shear stress cannot be derived, a free stream velocity $\left(\mathrm{U}_{\infty}\right)$ is most frequently used to indicate the relative flow strength between different runs. However, a velocity for the threshold condition $\left(U_{\infty}\right)$ is seldom given. Therefore the ratio $U_{o d} U_{\text {ot }}$ cannot be calculated and used as a proxy for the dimensionless friction velocity $u * u *$.

Observations from the two groups differ in several ways. Above the short patches concentration profiles decline more slowly with height than above the downstream end of the long granular beds. Within each group concentration profiles obtained for different wind strength show consistent behaviour (similarity). However, the grain velocity profiles are more diverse. Between 5 and $50 \mathrm{~mm}$ above the downstream bed of the short granular patches, the velocity increases more steeply with height than above the longer ones. Above $50 \mathrm{~mm}$ the relative difference between observations from the two groups is relatively small $(<20 \%)$. Because mass flux density is equivalent to the concentration at a given height multiplied by the grain velocity at the same height, the flux profiles are necessarily steeper above the short patches than above the long ones.

In studies in long wind tunnels saturated saltation in equilibrium with the wind tunnel flow requires an $\sim 15$-m-long fetch (Walker, 1981; Shao and Raupach, 1992). On the first 4-6 m of the granular bed, they observed a particularly strong overshoot of saltation transport. Careful design of the entry section may shorten this distance but not remove it totally. Therefore 
we suggest that one consider the studies made on the short patches to represent transitional conditions at the upwind end of a granular surface where saltation builds up. The flux here is larger than downstream on an (infinitely) long granular bed; concentration profiles are steeper and trajectories reach greater height such that grains gain more horizontal momentum than in the equilibrium saltation farther downstream. Because observations are made within a transition zone, they may depend on the particular length of the upwind patch, but this has not been studied here.

Laboratory studies of the splash have for many years contributed to the understanding of the saltation process. The conversion of momentum from the horizontal to the vertical direction is fundamental in order to compensate for the frictional energy loss during the ascending phase of the jump. Expressed in terms of the (vertical) coefficient of restitution $\left(e_{z}\right)$ for an incoming particle, it is found to increase with decreasing impact angle and exhibits values $>1$ for an impact angle smaller than $20^{\circ}$. Furthermore, when an incoming particle impacts the bed, it may not only rebound but also eject other particles that fly off in all directions with a speed that rarely exceeds $10 \%$ of the incident velocity. The experimental data indicate that the number of splashed particles at a given impact angle increases linearly with the impact speed above a threshold velocity $\left(\xi_{c} \approx \alpha \sqrt{g d}\right)$, which constrains the splash process to be predominantly driven by the transport of momentum rather than energy. To this we add that grain transport and form drag from ripples extract momentum from the wind flow that results in an increase in roughness that is proportional to the excess Shields' parameter 
(or the square of the excess friction velocity). This ties the wind speed at the cm-scale, i.e., in the most intensive part of the saltation cloud to an almost fixed value in a focal region (Bagnold's focal point).

The variation of grain speed with height, as recorded from experimental studies, is complex. However, for the data obtained above the long granular beds the observed grain speeds deviate only slightly from air speed such that as a first-order approximation it is reasonable to assume that grain speed is constant and constrained by the air speed in the focal region, i.e., almost invariant with shear stress. Consequently mass flux may be estimated by multiplying grain concentration with a typical grain speed. Hence contrary to the assumption made by Bagnold (1941) and Owen (1964) in their work, the laboratory studies made in long wind tunnels at low or moderate shear stresses indicate that flux must be approximately proportional to the Shields parameter or friction velocity squared and not cubed. Recent laboratory work (e.g., Beladjine et al., 2007; Ho et al., 2014), numerical modelling (Dúran et al., 2014) as well as a re-interpretation made by Dúran et al. (2011) of observations made by Iversen and Rasmussen (1999) gives broad experimental support for this relationship. As the saltation cloud may expand to higher elevation above the bed at increasing friction velocities, we expect that this could progressively change the exponent of Shields parameter toward 1.5. While traditionally many aeolian studies use friction velocity as a useful indicator in describing the dynamics, recent laboratory investigations point toward the Shields parameter as a more general tool that could also incorporate environmental parameters, 
such as temperature (McKenna Neuman, 2004) and particle density (i.e., varying mineralogy). Theoretical reasoning indicate that scaling with $\sqrt{g D_{p}}$ may account for the influence from grain size in, e.g., flux density (Dúran et al., 2011); but the experimental evidence for this seems limited at the present stage, and this is clearly a field for further investigation.

Besides the spatial transition discussed above, temporal transition on a granular bed may also influence results. Yet once transport begins limited information is available on the transitional behaviour of the saltating cloud, whereas the collective behaviour as expressed in the temporal development of ripple patterns has been investigated in several laboratory studies. Walker (1981) observed in the laboratory that for uniform samples that there is an intermediate particle size range $(0.25-0.40 \mathrm{~mm})$ for which the ripple spacing increase from 5-6 to 7-8 $\mathrm{cm}$ between the threshold of motion and the transition to the flat-bed regime. Corroborating field observations of this modest increase in spacing was made by Sharp (1963).

On a 0.12-mm bed, Andreotti et al. (2006) observed that after an initial coarsening of the pattern this tends to saturate at a finite wavelength that depends on friction velocity. Recent studies in the Aarhus wind tunnel indicate that for high shear stresses the time to saturation may be a few min. For low stresses it may take more than an hour. Actually Andreotti et al. (2006) specified this as a possible bias in their study. Ripple spacing is observed to increase as bed particles become finer (Fig. 16), but the observed influence from increasing $u *$ is larger in the Andreotti et al. (2006) experiment than in any of the other studies. For beds composed of sand of 
different diameter, Iversen and Rasmussen (1999) observed that interparticle forces resulted in a larger angle of repose for the small $(0.125 \mathrm{~mm})$ particles than for the larger particles. Clearly more work is needed to establish a firm knowledge of the behaviour of finer particles as compared to the intermediate size range of uniform sands.

The average saltation jump length that is observed on beds composed of uniform sands in the intermediate range is similar to the measured ripple length, and the laboratory observations are in excellent agreement with recent predictions based on a direct numerical simulation of grains acting with wind flow (Dúran et al., 2014). Their analysis indicates that ripple spacing is determined by resonant grain trajectories whose length is close to the ripple spacing. Saltation impact takes place in an interfacial layer above the static sand bed and the splash of the salting grains leads to a mass displacement toward ripple crests. According to Durán et al. (2014), the translation of the ripples may be taken as a proxy for mass transport.

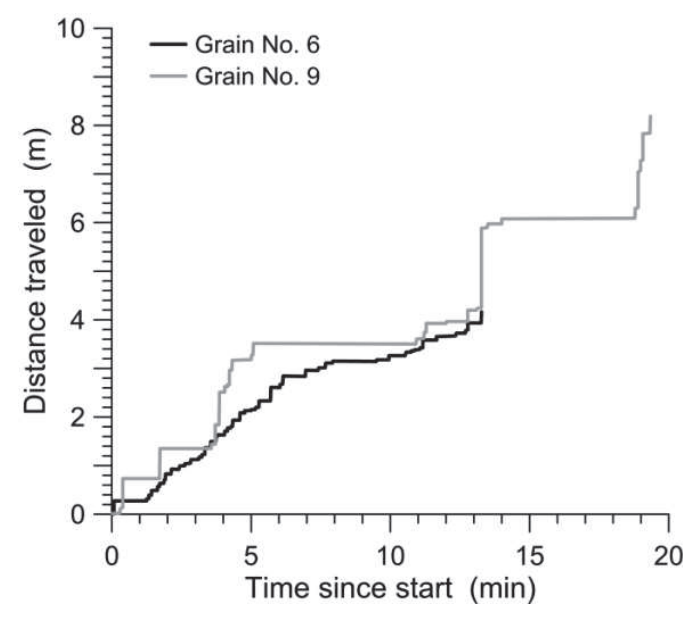

Fig. 20. The downstream displacement with time of two gold-coated quartz grains released at the upwind end of the Aarhus wind tunnel under a 
constant friction velocity near $0.4 \mathrm{~m} / \mathrm{s}$. Grain no. 9 belongs to the fine fraction, while grain no. 6 belongs to the coarse fraction.

Apart from bridging between experimental observations of ripple spacing and grain trajectories, the work by Dúran et al. (2014) also provides evidence for an interpretation of the ripple migration process, which was deduced from a saltation experiment made in the Aarhus wind tunnel (Barndorff-Nielsen et al., 1985). About 30 quartz grains with diameter between 0.28 and $0.48 \mathrm{~mm}$ were coated with gold, marked radioactively, and then one-by-one placed at the upwind end of the tunnel. From here the downstream displacement along the bed was followed with a Geiger counter. The movement of grains no. 6 and no. 9 represent some typical saltation characteristics (Fig. 20).

We interpret no. 9 as a typical saltating grain that makes long excursions composed of several or many jumps but occasionally coming to rest in a trough region downstream of a crest. When one or several ripples have moved past the grain it is reactivated and performs a new series of jumps. Not all ripples have the same amplitude, so occasionally the grain has to wait until one of the deeper troughs will expose it once more to impacting grains. Occasionally it makes short jumps and is buried at shallow depth among coarser grains on the stoss side of a ripple. Here it lies shielded for a time before being exposed once more to impact from saltating grains and reactivated. Contrary to this behaviour, the larger grain no. 6 primarily moves in creep or short jumps (reptation, Anderson et al., 1991) 
caused by impacts from saltating grains. Resting periods are generally short because it stays on the stoss side or crest region most of the time. However, after $8 \mathrm{~min}$ it is splashed into the trough in front of the ripple where it is buried for a considerable time before being exposed again and hit with enough momentum to continue its creeping motion. Finally after $13 \mathrm{~min}$ it comes to rest in a (deep) trough and stays at the same position during the remaining part of the 20 -min run. All together we therefore conclude that the experimental data and the model predictions by Dúran et al. (2014) are in excellent agreement and both favour a concept of the ripples representing the active transport layer.

Electrification is seen as a dominant factor in the transport dynamics of dust, affecting the structure, adhesive properties, and detachment/entrainment mechanisms specifically through the formation of aggregates (Merrison et al., 2012). For sand, however, the degree of electrification and the electric fields typically generated (observed) in nature are not intense enough to significantly affect transport rates or thresholds (Rasmussen et al., 2009; Bo et al., 2013). This may not necessarily be the case for extraterrestrial environments. Clearly a large contribution to the present knowledge about aeolian processes on Earth comes from welldesigned laboratory work. Relatively precise predictions about the behaviour of mass transport by saltation can be made today although knowledge regarding, for instance, the influence of particle size - in particular the finest and coarsest fractions, still is lacking. 
In a Martian context the observed wind thresholds for dust and sand transport generally agree with those recreated in the laboratory and also predicted by theoretical models. However, the scientific community is still far from being able to describe saltation on Mars quantitatively, i.e., predict transport rates, ripple structure (lengths), splash, etc. (see Yizhaq et al., 2014).

Some studies (e.g., Almeida et al., 2008) indicate that the saltation length (and therefore ripple length) on Mars is a factor of 10-100 times longer than that on Earth, also that they consist of significantly larger grain diameter (around $600 \mu \mathrm{m}$ ) and that this occurs at high wind speeds (of 2-41 $\mathrm{m} / \mathrm{s}$ ). This however is not supported by observations from the surface of Mars, which show that active ripples on Mars have a wave length of $10 \mathrm{~cm}$ or less and consist of grains around 100-300 $\mu \mathrm{m}$, i.e., similar to terrestrial ripples (Sullivan et al., 2008). Also the highest average wind speeds on Mars have been measured to be $<20 \mathrm{~m} / \mathrm{s}$, with even turbulent gusts not exceeding $25 \mathrm{~m} / \mathrm{s}$. Although other larger scale sand bed formations are observed on Mars (classed as coarse-grained ripples or mega ripples), these are seen to be indurated (i.e., not active) and are thought to be formed by creep or may even be dunes (Bourke et al., 2010). Interestingly evidence is seen for occasional sand entrainment events to heights of $>0.66 \mathrm{~m}$; however, similar effects are also observed on Earth for saltation on nonerodible beds (e.g., Bridges et al., 2012a; Ho et al., 2014).

In other modelling of saltation on Mars, Kok (2010) suggests that the dynamic threshold (for sustaining saltation) is as much as an order of 
magnitude lower than the fluid threshold. Again, however, this does not seem to be consistent with observations from Mars where saltation is seen to be sporadic and infrequent (not self-sustaining once initiated). In conclusion, more work is clearly needed to resolve these inconsistencies, which should include not just observation and theory but also laboratory simulations.

Although saltation-induced abrasion has not been addressed in this work, this is a subject of some interest to the environment and one would expect there to be a relationship between saltation transport rate and abrasion rate. It is worth mentioning here that from recent progress in comparing various laboratory studies of abrasion it is becoming clear that impact velocity as well as transport rate may be a crucial parameter in the process of abrasion. Specifically three regimes appear to exist: for avalanche type processes where impact velocities are around $0.3 \mathrm{~m} / \mathrm{s}$ abrasion appears to be negligible (de Vet, 2013); for impact velocities of around $1 \mathrm{~m} / \mathrm{s}$ active abrasion occurs through chipping and the direct production of dust/silt (Merrison, 2012); and at higher impact velocities (around $10 \mathrm{~m} / \mathrm{s}$ ) fracturing and eventual sand grain disintegration dominates (e.g., Greeley and Iversen 1985).

Finally we wish to draw attention to some important unanswered questions where laboratory work can have an important role to play. So far very little is known about the dynamics in unsaturated saltation where the dominant collision is between the saltating grains and a hard bed. Likewise knowledge of the influence from varying grain size (mixed or broad grain 
size distributions) is only superficially understood. Armouring is an important element at some (low or moderate) fluid shear stresses, and segregation of grains during transport also influences saltation dynamics not only during steady state conditions but also in the transitional stages when the saltation cloud develops from an initially quiescent bed. Scattered pieces of information have been collected, but we think that currently we are still some distance away from a general frame of reference.

In a planetary context there is a need to better understand how varying fundamental physical parameters such as fluid density, molecular viscosity, and gravity affect the transport of sediments (and the use of semiempirical models). Specifically, wind tunnel studies could contribute greatly in this regard (at present) by, for example, detailed studies of saltation and dust entrainment at different pressures, gas compositions, and material properties. Such activities are in their infancy.

\section{Acknowledgements}

We acknowledge Andreas Boes Jakobsen and Jens Jacob Iversen for their help and support with the experimental work in the Aarhus wind tunnel. We would like to thank Pascal Dupont, Ahmed Ould El Mochtar, and Marc Lämmel for fruitful discussion during the workshop 'Fluid-Mediated Particle Transport in Geophysical Flows', 2013-09-23 to 2013-12-20 at the Kavli Institute, UCSB. Marc Lämmel also derived Fig. 17B from our 
experimental data. We also acknowledge two anonymous reviewers for the valuable comments and suggestions.

\section{References}

Al-Nassar, W., Alhajraf, S., Al-Sudairawi, M., Joseph, G., Rasmussen, K.R., 2002. KISR Long Atmospheric Boundary Layer Wind Tunnel. Proceedings of ICAR5/GCTE-SEN Joint Conference, International Center for Arid and Semiarid Lands Studies, Texas Tech University, Lubbock, Texas, USA. Publ. 02-2, p. 74.

Almeida, M.P., Parteli, E.J.R., Andrade, J.S., Hermann, H.J., 2008. Giant saltation on Mars. Proceedings of the National Academy of Sciences 105, 6222-6226.

Ammi, M., Oger, L., Beladjine, D., Valance, A., 2009. Three-dimensional analysis of the collision process of a bead on a granular packing. Physical Review E 79, 021305.

Anderson, R.S., Haff, P.K., 1988. Simulation of eolian saltation. Science 241, 820-823. doi: 10.1126/science.241.4867.820 
Anderson, R.S., Sorensen, M., Willetts, B.B., 1991. A review of recent progress in the understanding of aeolian sediment transport. Acta Mechanica, (Suppl. 1), 1-19.

Andreotti, B., Claudin, P., Pouliquen, O., 2006. Aeolian Sand Ripples: Experimental Study of Fully Developed States. Physical Review Letters 96, 02800, 1-4.

Andreotti, B., Claudin, P., Pouliquen, O., 2010. Measurements of the aeolian sand transport saturation length. Geomorphology 123, 343348.

Arvidson, R.E., Guinness, E.A., Moore, H.J., Tillman, J., Wall, S.D., 1983. Three Mars years: Viking lander 1 imaging observations. Science $222,463-468$.

Ayoub, F., Avouac, J.P., Newman, C.E., Richardson, M.I., Lucas, A., Leprince, S., Bridges, N.T., 2014. Threshold for sand mobility on Mars calibrated from seasonal variations of sand flux. Nature Communications 5, 5096. doi:10.1038/ncomms6096

Bagheri, G.H., Bonadona, C., Manzella, I., Vonlanthen, P., 2014. On the characterization of size and shape of irregular particles. Powder Technology 270, 141-153. 
Bagnold, R.A., 1936. The movement of desert sand. Proceedings Royal Society London A 157, 594-620.

Bagnold, R.A., 1937. The Size-Grading of Sand by Wind. Proceedings Royal Society London A 163, 250-264.

Bagnold, R.A., 1938. The Measurement of Sand Storms. Proceedings Royal Society London A 167, 282-291.

Bagnold, R.A., 1941. The physics of blown Sand and Desert Dunes. Methuen, London (265 pp.).

Balme, M., Greeley, R., 2006. Dust devils on earth and Mars. Reviews of Geophysics 44, RG3003.

Barndorff-Nielsen, O.E., Jensen, J.L., Loft-Nielsen, H., Rasmussen, K.R., Sørensen, M., 1985. Wind tunnel tracer studies of grain progress. Memoirs no. 8, Department of Theoretical Statistics, Aarhus University, Denmark, pp. 243-253.

Bauer, B.O., Houser, C.A., Nickling, W.G., 2004. Analysis of velocity profile measurements from wind-tunnel experiments with saltation. Geomorphology 59, 81-98. 
Bauer, B.O., Walker, I.J., Baas, A.C.W., Jackson, D.W.T., McKenna

Neuman, C., Wiggs, G.F.S., Hesp, P.A., 2013. Critical Reflections

on the Coherent Flow Structures Paradigm in Aeolian

Geomorphology. In: Venditti, J.G., Best, J.L., Church, M., Hardy.

R.J. (Eds.), Coherent Flow Structures at Earth's Surface. Wiley, pp. $111-134$.

Beladjine, D., Ammi, D., Oger, L., Valance, A., 2007. Collision process between an incident bead and a three-dimensional granular packing. Physical Review E 75, 061305.

Bo, T., Zheng, X., Duan, S., Liang, Y., 2013. Analysis of sand particles' lift-off and incident velocities in wind-blown sand. Acta Mechanica Sinica 29, 158-165.

Bourke, M.C., Lancaster, N., Fenton, L.K., Parteli, E.J.R., Zimbelman, J.R., Radebaugh, J., 2010. Extraterrestrial dunes: An introduction to the special issue on planetary dune systems. Geomorphology 121, 114.

Bradshaw, P., Pankhurst, R.C., 1964. The design of low-speed wind tunnels. Progress Aeronautical Science 5, 1. 
Bridges, N.T., Geissler, P.E., McEwen, A.S., Thomson, B.J., Chuang, F.C., Herkenhoff, K.E., Keszthelyi, L.P., Martınez-Alonso, S., 2007. Windy Mars: A dynamic planet as seen by the HiRISE camera. Geophysical Research Letters 34, L23205.

Bridges, N.T., Ayoub, F., Avouac, J-P., Leprince S., Lucas A., Mattson S., 2012a. Earth-like sand fluxes on Mars. Nature 485, 339-342. doi:10.1038/nature11022.

Bridges, N.T., Bourke, M.C., Geissler, P.E., Banks, M.E., Colon, C., Diniega, S., 2012b. Planet-wide sand motion on Mars. Geology 40, $31-44$.

Brutsaert, W.H., 1982. Exchange processes at the earth-atmosphere interface. In: Plate, E.J. (Ed.), Engineering Meteorology, Elsevier, pp.319-369.

Butterfield, G.R., 1999. Near-bed mass flux profiles in aeolian sand transport. Earth Surface Processes and Landforms 24, 393-412.

Camenen, B., Bayram, A., Larson, M., 2006. Equivalent Roughness Height for Plane Bed under Steady Flow. Journal Hydraulic Engineering 132, 1146-1158. 
Chepil, V.S., 1965. Transport of Soil and Snow by Wind. Meteorological Monographs 6, 123-132.

Coles, D.E., 1956. The law of the wake in the turbulent boundary layer. Journal Fluid Mechanics 1, 191-226.

Crassous, J., Beladjine, D., Valance, A., 2007. Impact of a Projectile on a Granular Medium Described by a Collision Model. Physical Review Letters 99, 248001.

Creyssels, M., Dupont, P., Ould-El-Mochtar, A., Valence, A., Cantat, I., Jenkins, J.T., Rasmussen, K.R., 2009. Saltating particles in a turbulent boundary layer: experiment and theory. Journal Fluid Mechanics 625, 47-74.

de Vet, S., 2013. When the Glacier left the volcano; Behaviour and fate of glacio-volcanic glass in different planetary environments. $\mathrm{PhD}$ dissertation, University of Amsterdam, The Netherlands. ISBN: 978-94-91407-11-6.

Dong, Z., Liu, X., Wang, H., Wang, X., 2003. Aeolian sand transport: a wind tunnel model. Sedimentary Geology 161, 71-83. 
Dong, Z., Liu, X., Wang, X., Li, F., Zhao, A.H., 2004. Experimental investigation of the velocity of a sand cloud blowing over a sandy surface. Earth Surface Processes and Landforms 29, 343-358.

Dong, Z., Qian, G., Luo, W., Wang, H., 2006. Analysis of the mass flux profiles of an aeolian saltating cloud. Journal of Geophysical Research 111, D16111.

Durán, O., Claudin, P., Andreotti, B., 2011. On aeolian transport: Grainscale interactions, dynamical mechanisms and scaling laws. Aeolian Research 3, 243-270.

Durán, O., Claudin, P., Andreotti, B., 2014. Direct numerical simulations of aeolian sand ripples. Proceedings of the National Academy of Sciences 111, 15665-15668.

Ellis, J.T., Morrison, R.F., Priest, B.H., 2009. Measuring the transport of aeolian sand with a microphone system. Geomorphology 105, 8794.

Ellwood, J.M., Evans, P.D., Wilson, I.G., 1975. Small scale aeolian bedforms. Journal Sedimentary Petrology 45, 554-561. 
Gillette, D.A., Stockton, P.H., 1986. Mass, Momentum and Kinetic Energy Fluxes of Saltating Particles. In: Nickling, W.G. (Ed.), Aeolian Geomorphology. Allen and Unwin, Boston, pp. 35-56.

Gillette, D.A., Herbert, G., Stockton, P.H., Owen, P.R., 1996. Causes of the fetch effect in wind erosion. Earth Surface Processes and Landforms 21, 641-659.

Greeley, R. 1977. The Martian Surface Wind Tunnel (MARSWIT). Univ. Santa Clara-NASA-ARC-009-E (Articles.adsabs.harvard.edu).

Greeley, R., 2002. Saltation impact as a means for raising dust on Mars. Planetary and Space Science 50, 151-155.

Greeley, R., Iversen, J.D., 1985. Wind as a Geological Process on Earth, Mars and Venus. Cambridge Planetary Science Series, Cambridge University Press (333 pp.).

Greeley, R., Leach, R., White, B.R., Iversen, J.D., Pollack, J.B., 1980. Threshold windspeeds for sand on Mars: wind tunnel simulations. Geophysical Research Letters 7, 121-124.

Greeley, R., Blumberg, D.G., Williams, S., 1996. Field measurements of the flux and speed of wind-blown sand. Sedimentology 43, 41-52. 
Greeley, R., Bender, K.C., Saunders, R.S., Schubert, G., Simpson, R.A., 1997. Aeolian processes and features of Venus. In: Bougher, S.W., Hunten, D.M., Phillips, R.J. (Eds.), Venus II. Geology, geophysics, atmosphere, and solar wind environment. University of Arizona Press, Tucson, pp. 547-589.

Gross, F.B., Grek, S.B., Calle, I.C., Lee, R.U., 2001. JSC Mars-1 Martian regolith simulant particle charging experiments in low pressure environment. Journal of Electrostatics 53, 257-266.

Ho, T.D., Valance, A., Dupont, P., Ould El Moctar, A., 2014. Aeolian sand transport: Length and height distribution of saltation trajectories. Aeolian Research 12, 65-74.

Holstein-Rathlou, C., Gunnlaugsson, H.P., Merrison, J.P., Bean, K.M., Cantor, B.A., Davis, J.A., Davy, R., Drake, N.B., Ellehoj, M.D., Goetz, W., Hviid, S.F., Lange, C.F., Larsen, S.E., Lemmon, M.T., Madsen, M.B., Malin, M., Moores, J.E., Nørnberg, P., Smith, P., Tamppari, L.K., Taylor, P.A., 2010. Winds at the Phoenix landing site. Journal of Geophysical Research 115, E00E18. 
Holstein-Rathlou, C., Merrison, J. P., Brædstrup, C. F., Nørnberg, P., 2012. The effects of electric fields on wind driven particulate detachment. Icarus 220, 1-5. doi:10.1016/j.icarus.2012.04.011

Holstein-Rathlou, C., Merrison, J. P., Iversen, J.J., Jakobsen, A.B., 2014. An Environmental Wind Tunnel Facility for Testing Meteorological Sensor Systems. American Meteorological Society 31, 447.

Horikawa, K., Shen, H.W., 1960. Sand movement by wind. U.S. Army Corps of Engineers, Beach erosion board, Technical Memorandum No. 119 (51 pp.).

Irwin, H.P.A.H., 1981. The design of spires for wind simulation. Journal of Wind Engineering and Industrial Aerodynamics 7, 361-366.

Ishida, Y., 1923. Determination of viscosities and of the Stokes-Millikan Law constant by the oil drop method. Physical Review 21, 550563.

Iversen, J.D., 1976. Saltation threshold on Mars: The effect of interparticle force, surface roughness, and low atmospheric density. Icarus 29, 381-393. 
Iversen, J.D., Rasmussen, K.R., 1994. The effect of surface slope on saltation threshold. Sedimentology 41, 721-728.

Iversen, J.D., Rasmussen, K.R., 1999. The effect of wind speed and bed slope on sand transport. Sedimentology 46, 723-731.

Iversen, J.D., White, B.R., 1982. Saltation threshold on Earth, Mars and Venus. Sedimentology 29, 111-119.

Jackson, T.L., Farrell, W.M., 2006. Electrostatic fields in dust devils: An analog to Mars. IEEE Transactions on Geoscience and Remote Sensing 44, 2942-2949.

Jensen, M., 1954. Shelter effect: investigations into aerodynamics of shelter and its effects on climate and crops. Danish Technical Press, Copenhagen (264 pp.).

Kahn, R.A., Martin, T.Z., Zurek, R.W., Lee, S.W., 1992. The Martian dust cycle. In: Kieffer, H.H., Jakosky, B.M., Snyder, C.W., Mathews, M.S. (Eds.), Mars. University of Arizona Press, Tucson, pp. 10171053. ISBN 0-8165-1257-4.

Kang, L.Q., Guo, L.J., Liu, D.Y., 2008. Experimental investigation of particle velocity distributions in windblown sand movement. 
Science in China Series G — Physics Mechanics and Astronomy 51, 986-1000.

Kawamura, R., 1951, Study on Sand Movement by Wind (in Japanese). Report 5, Institute of Science and Technology, Tokyo, 95-112. Translated as Report HEL-2-8 (1965), University of California Hydraulics Engineering Laboratory, Berkeley (38 pp.).

Kok, J.F., 2010. An improved parameterization of wind-blown sand flux on Mars that includes the effect of hysteresis. Geophysical Research Letters 37, L12202.

Kok, J.F., Lacks, D.J., 2009. Electrification of granular systems of identical insulators. Physical Review E 79, 051304.

Kok, J.F., Renno, N.O., 2006. Enhancement of the emission of mineral dust aerosols by electric forces. Geophysical Research Letters 33, L19S10.

Kok, J.F., Renno, N.O., 2008a. Electrostatics in wind-blown sand. Physical Review Letters 100, 014501.

Kok, J.F., Renno, N.O., 2008b. Electrical activity and dust lifting on Earth, Mars, and beyond. Space Science Reviews 137, 419-434. 
Lacks, D.J., Levandovsky, A., 2007. Effect of particle size distribution on the polarity of triboelectric charging in granular insulator systems. Journal of Electrostatics 65, 107-112.

Lacks, J.D., Duff, N., Kumar, S.K., 2008. Nonequilibrium accumulation of surface species and triboelectric charging in single component particulate systems. Physical Review Letters 100, 188305.

Lettau, H.H., Lettau, K., 1978. Experimental and micrometeorological field studies of dune migration. In: Lettau, H.H., Lettau, K. (Eds.), Exploring the world's driest climate. IES Report no. 101, Institute for Environmental Studies, University of Wisconsin-Madison, pp. $67-73$

Lemmon, M.T., Wolff, M.J., Smith, M.D., Clancy, R.T., Banfield, D., Landis, G.A., Ghosh, A., Smith, P.H., Spanovich, N., Whitney, B., Whelley, P., Greeley, R., Thompson, S., Bell III, J.F., Squyres, S.W., 2004. Atmospheric imaging results from the Mars exploration rovers: Spirit and Opportunity. Science 306, 17531756. 
Li, B., McKenna Neuman, C., 2014. A wind tunnel study of aeolian sediment transport response to unsteady winds. Geomorphology 214, 261-269.

Liu, X., Dong, Z., 2004. Experimental investigation of the concentration profile of a blowing sand cloud. Geomorphology 60, 371-381.

Lorenz, R.D., Radebaugh, J., 2009. Global pattern of Titan's dunes: radar survey from the Cassini prime mission. Geophysical Research Letters 36, L03202. doi:10.1029/2008/GL036850.

Lorenz, R.D., Zimbelman, J.R., 2014. Dune Worlds: How Windblown Sand Shapes Planetary Landscape. Springer Praxis Books - Geophysical Sciences 21 (308 pp.).

Lowell, J., 1986. Constraints on contact charging of insulators: I. Spatial localization of insulator states. Journal of Physics D: Applied Physics 19, 95-104.

Maeno, N., Naruse, R., Nishimura, K., Takei, I., Ebinuma, T., Kobayashi, S., Nishimura, H., Kaneda, Y., Ishida, T., 1985. Wind-tunnel experiment on blowing snow. Annals of Glaciology 6, 63-67. 
McKenna Neuman, C., 2004. Effects of temperature and humidity upon the transport of sedimentary particles by wind. Sedimentology 51, 117.

McKenna Neuman, C., Nickling, W.G., 1994. Momentum extraction with saltation: Implications for experimental evaluation of wind profile parameters. Boundary-Layer Meteorology 68, 35-50.

McKenna Neuman, C., Sanderson, S., 2008. Humidity control of particle emissions in aeolian systems. Journal of Geophysical Research 113, F02S14.

McKenna Neuman, C., Scott, M.M., 1998. A wind tunnel study of the influence of pore water on aeolian sediment transport. Journal of Arid Environments 39, 403-419.

McKenna Neuman, C., Li, B., Nash, D., 2012. Aeolian laboratory, saltation, splash, planetary laboratory, Journal of Geophysical Research 117, F04003.

Merrison, J.P., 2012. Sand transport, erosion and granular electrification, Aeolian Research 4, 1-16. 
Merrison, J.P., Gunnlaugsson, H.P., Jensen, S.J.K., Nørnberg, P., 2010. Mineral alteration induced by sand transport; a source for the reddish colour of Martian dust. Icarus 205, 716-718.

Merrison, J., Jensen, J., Kinch, K., Mugford, R., Nørnberg, P., 2004. The electrical properties of Mars analogue dust. Planetary and Space Science 52, 279-290.

Merrison, J.P., Gunnlaugsson, H.P., Nørnberg, P., Jensen, A.E., Rasmussen, K.R., 2007. Determination of the Wind Induced Detachment Threshold for Granular Material on Mars using Wind Tunnel Simulations. Icarus 191, 568-580.

Merrison, J.P., Bechtold, H., Gunnlaugsson, H.P., Jensen, A., Kinch, K., Nørnberg, P., Rasmussen, K., 2008. An Environmental Simulation Wind Tunnel for Studying Aeolian Transport on Mars. Planetary and Space Science 56, 426-437.

Merrison, J.P., Gunnlaugsson, H.P., Hogg, M.R., Jensen, M., Lykke, J.M., Madsen, M.B., Nielsen, M.B., Nørnberg, P., Ottosen, T.A., Pedersen, R.T., Pedersen, S., Sørensen, A.V., 2012. Factors affecting the electrification of wind-driven dust studied with laboratory simulations. Planetary and Space Science 60, 328-335. 
Mitha, S., Tran, M.Q., Werner, B.T., Haff, P.K., 1986. The grain-bed impact process in aeolian. Acta Mechanica 63, 267.

Moulin, C., Lambert, C.E., Dulac, F., Dayan, U., 1997. Control of atmospheric export of dust from North Africa by the North Atlantic oscillation. Nature 387 (6634), 691-694.

Mulholland, D.P., Read, P.L., Lewis, S.R., 2013. Simulating the interannual variability of major dust storms on Mars using variable lifting thresholds. Icarus 223, 344-358.

Nalpanis, P., Hunt, J., Barrett, C., 1993. Saltating particles over flat beds. Journal of Fluid Mechanics 251, 661.

Namikas, S.L., Bauer, B.O., Sherman, D.J., 2003. Influence of averaging interval on shear velocity estimates for aeolian transport modeling. Geomorphology 53, 235-246.

Nickling, W.G., McKenna Neuman, C., 1997. Wind tunnel evaluation of a wedge-shaped aeolian sediment trap. Geomorphology 18, 333-345.

Oger, L., Ammi, M., Valance, A., Beladjine, D., 2005. Discrete Element Method studies of the collision of one rapid sphere on 2D and 3D packings. The European Physical Journal E 17, 467-476. 
Owen, P.R., 1964. Saltation of uniform grains in air. Journal of Fluid Mechanics 20, 225-242.

Owen, P.R., 1980. The physics of sand movement. Trieste: International Centre for Theoretical Physics. (Lecture notes, Workshop on physics of flow in deserts).

Owen, P.R., Gillette, D.A., 1985. Wind tunnel constraint on saltation. Memoirs no. 8, Department of Theoretical Statistics, Aarhus University, Denmark, pp. 253-269.

Poppe, T., Blum, J., Henning, T., 2000. Experiments on collisional grain charging of micron-sized preplanetary dust. Astrophysical Journal $533,472-480$.

Pye, K., Tsoar, H., 2009. Aeolian Sand and Sand Dunes (2 ${ }^{\text {nd }}$ ed.). Springer, Berlin (476 pp.).

Perko, H.A., 2002. Theoretical and experimental investigations in planetary dust adhesion. Ph.D. Dissertation, Colorado State University. Civil Engineering Department, Colorado State University, Fort Collins, CO. 
Rader, D.J., 1990. Momentum slip correction factor for small particles in nine common gases. Journal of Aerosol Science 21, 161-168.

Rasmussen, K.R., Mikkelsen, H.E., 1991. Wind tunnel observations of aeolian transport rates. Acta Mechanica (Suppl. 1), 135-144.

Rasmussen, K.R., Mikkelsen, H.E., 1998. On the efficiency of vertical array aeolian field traps. Sedimentology 45, 789-800.

Rasmussen, K.R., Sørensen, M., 2008. The vertical variation of particle speed and flux density in aeolian saltation: Measurement and modelling. Journal of Geophysical Research 113, F02S12.

Rasmussen, K.R., Iversen, J.D., Rautaheimo, P., 1996. Saltation and wind flow interaction in a variable slope wind tunnel. Geomorphology 17, 19-28.

Rasmussen, K.R., Kok, J.F., Merrison, J.P., 2009, Enhancement in winddriven sand transport by electric fields. Planetary and Space Science 57, 804-808.

Rasmussen, K.R., Merrison, J.P., Nørnberg, P., 2011. Wind Tunnels for the Study of Particle Transport. In: Lerner, J.C., Boldes, U. (Eds.), 
Wind Tunnels and Experimental Fluid Dynamics Research. InTech Rijeka, Croatia 2011, pp. 51-74.

Raupach, M.R., Antonia, R.A., Rajagopalan, S., 1991. Rough-wall turbulent boundary layers. Applied Mechanics Reviews 44, 1-25.

Rice, M.A., Willetts, B.B., McEwan, I.K., 1996. Observations of collisions of saltating grains with a granular bed from high-speed cine-film. Sedimentology 43, 21-31.

Rioual, F., Valance, A., Bideau, D., 2003. Collision process of a bead on a two-dimensional bead packing: Importance of the inter-granular contacts. Europhysics Letters 61, 194.

Schlichting, H., 1979. Boundary Layer Theory 7th ed. McGraw-Hill, New York (817 pp.).

Schmidt, D.S., Schmidt, R.A., Dent, J.D., 1999. Electrostatic force in blowing snow. Boundary-Layer Meteorology 93, 29-45.

Seppälä, M., Lindé, K., 1978. Wind tunnel studies of ripple formation. Geografiska Annaler Ser. A, Physical Geography 60, 29-42. 
Shao, Y., Li, A., 1999. Numerical modelling of Saltation in the Atmospheric Surface Layer. Boundary-Layer Meteorology 91, 199-225.

Shao, Y., Lu, H., 2000. A simple expression for wind erosion threshold friction velocity. Journal of Geophysical Research 105, 2243722443.

Shao, Y., Raupach, M.R., 1992. The Overshoot and Equilibration of Saltation. Journal of Geophysical Research 97, 20559-20564.

Sharp, R.P., 1963. Wind ripples. The Journal of Geology 71, 617-636.

Sherman, D.J. 1992. An equilibrium relationship for shear velocity and apparent roughness length in aeolian saltation. Geomorphology 5, $419-431$

Sherman, D.J., Li, B., Farrell, E.J., Ellis, J.T., Cox, W.T., Maia, L.P., Sousa, P.H.G.O., 2011. Measuring Aeolian Saltation: A Comparison of Sensors. Journal of Coastal Research 10059, 280-290.

Sickafoose, A.A., Colwell, J.E., Horányi, M., Robertson, S., 2001. Experimental investigations on photoelectric and triboelectric charging of dust. Journal of Geophysical Research 106, 8343-8356. 
Silvestro, S., Fenton, L.K., Vaz, D.A., Bridges, N.T., Ori, G.G., 2010.

Ripple migration and dune activity on Mars: Evidence for dynamic wind processes. Geophysical Research Letters 37, L20203. doi: 10.1029/2010GL044743

Spalding, D.B., 1961. A Single Formula for the 'Law of the Wall'. Journal Applied Mechanics 28, 455-458.

Stoy, R.D., 1995. Force on two touching dielectric spheres in a parallel field. Journal of Electrostatics 35, 297-308.

Sullivan, R.J., Arvidson, R., Bell III, J.F., Gellert, R., Golombek, M., Guinness, E., Greeley, R., Herkenhoff, K., Johnson, J., Squyres, S., Thompson, S., Whelley, P., Wray, J., 2008. Wind-driven particle mobility on Mars: Insights from Mars Exploration Rover observations at "El Dorado" and surroundings at Gusev Crater. Journal of Geophysical Research 113, E06S07.

Unger, J.E., Haff, P.K., 1987. Steady state saltation in air. Sedimentology 34, 289-299.

Walker, J.D., 1981. An experimental study of wind ripples. Thesis, Department of Earth and Planetary Sciences, Massachusetts Institute of Technology, (142 pp.). 
Werner, B.T., 1990. A steady-state model of wind-blown sand transport. The Journal of Geology 98, 1-17.

Werner, B.T., Haff, P.K., 1988. The impact process in aeolian saltation: two-dimensional studies. Sedimentology 35, 189-196.

Westoby, M.J., Brasington, J., Glasser, N.F., Hambrey, M.J., Reynolds, J.M., 2012. 'Structure-from-Motion“ photogrammetry: A low-cost, effective tool for geoscience applications. Geomorphology 179, $300-314$.

White, B.R., 1981. Low-Reynolds-Number Turbulent Boundary Layers. Journal of Fluids Engineering 103, 624-630.

White, F.M., 1991. Viscous Fluid Flow. McGraw Hill, New York (611 pp.).

Willetts, B.B., Rice, M.A., 1986. Collisions in aeolian transport: The saltation/creep link. In: Nickling, W.G. (Ed), Aeolian Geomorphology. Allen and Unwin, Boston, pp. 1-16.

Willetts, B.B., Rice, M.A., 1989. Earth Surface Processes and Landforms 14, 719 . 
Williams, G., 1964. Some aspects of the eolian saltation load.

Sedimentology 3, 257-287.

Yizhaq, H., Kok, J.F., Katra, I., 2014. Basaltic sand ripples at Eagle Crater as indirect evidence for the hysteresis effect in martian saltation. Icarus 230, 143-150.

Zhang, W., Wang, Y., Lee, S.J., 2008. Simultaneous PIV and PTV measurements of wind and sand particle velocities. Experiments in Fluids 45, 241-256.

Zheng, X.J., Huang, N., Zhou, Y., 2006. The effect of electrostatic force on the evolution of sand saltation cloud. European Physical Journal E $19,129-138$.

Zhigang, L., Wang, H., 2003. Drag force, diffusion coefficient, and electric mobility of small particles. I. Theory applicable to the freemolecule regime. Physical Review E 68, 061206.

Zimbelman, J.R., Bourke, M.C., Lorenz, R.D., 2013. Recent developments in planetary Aeolian studies and their terrestrial analogs. Aeolian Research 11, 109-126. 
Zingg, A.W., Chepil, W.S., 1950. Aerodynamics of Wind Erosion.

Agricultural Engineering 31, 279-284. 


\section{Appendix A: Notation}

$A, B, C$

$\mathrm{A}_{\mathrm{LDA}}$

$\beta$

$D_{p}$

d

$\delta$

E

e

$e_{z}$

$\varepsilon_{n}$

$\varepsilon_{0}$

$\mathrm{Fr}$

$\phi$

g

$\mathrm{H}$

$\mathrm{k}_{\mathrm{s}}$

$\kappa$

L

$\mathrm{L}_{\mathrm{F}}$

$l_{c}$

$l_{\phi}$

$l_{\text {sat }}$
Constants

Cross sectional area of laser

Constant

Particle diameter

Median particle diameter

Boundary layer thickness

Electric field strength

Restitution coefficient

Vertical restitution coefficient

Normal restitution coefficient

Permittivity of free space

Froude number

Mass flux density

Acceleration due to gravity

Wind tunnel height

Equivalent grain roughness

von Karman constant

Wind tunnel length

Fetch distance

Decay-length for particle concentration

Decay-length for mass flux density

Saturation length ‘ 
$\Lambda$

$\lambda$

$M_{0}$

$n$

$n_{e j}$

$\Omega_{\mathrm{p}}$

$v$

$v_{0}$

$\Pi$

$q$

$\mathrm{R} *$

r

$\rho, \rho_{p}$

$S^{*}$

$S_{t}$

$\theta_{i}$

$\theta_{r}$

$\tau$

$\tau_{t h}$

$\tau_{E}$

$U_{\infty}$

$U_{\text {ot }}$
Ripple spacing

Saltation jump length

Mass collected in first chamber of horizontal

trap

Rate of grains

Number (splashed particles)

Particle volume

Viscosity

Particle concentration at bed

Coles wake parameter

Saturated flux of sediment (sand)

Roughness Reynolds number

Grain radius

Densities

Shields parameter

Critical Shields parameter (dynamic threshold)

Impact angle

Mean rebound angle

Shear stress

Threshold shear stress

Electric field stress

Free stream velocity (air)

Threshold free stream velocity 


$\begin{array}{ll}u * & \text { Velocity (air) } \\ u * f b & \text { Friction velocity } \\ \widetilde{V}, \widetilde{V}_{x}, \widetilde{V}_{z} & \text { Critical friction velocity for flat-bed transition } \\ V_{i} & \text { Normalized velocities } \\ V_{r, I} & \text { Impact velocity (particle) } \\ V_{r, z} & \text { Vertical component of impacting speed } \\ \bar{V}_{x} & \text { Average horizontal take-off velocity } \\ \mathrm{W} & \text { Wind tunnel width } \\ z & \text { Elevation } \\ z_{0} & \text { Aerodynamic roughness } \\ \xi_{c} & \text { Critical velocity }\end{array}$

